\title{
Federal Fleet Resilience Planning
}

\section{Office of}

ENERGY EFFICIENCY \& RENEWABLE ENERGY

April 2021 


\section{Disclaimer}

This work was prepared as an account of work sponsored by an agency of the United States Government. Neither the United States Government nor any agency thereof, nor any of their employees, nor any of their contractors, subcontractors or their employees, makes any warranty, express or implied, or assumes any legal liability or responsibility for the accuracy, completeness, or any third party's use or the results of such use of any information, apparatus, product, or process disclosed, or represents that its use would not infringe privately owned rights. Reference herein to any specific commercial product, process, or service by trade name, trademark, manufacturer, or otherwise, does not necessarily constitute or imply its endorsement, recommendation, or favoring by the United States Government or any agency thereof or its contractors or subcontractors. The views and opinions of authors expressed herein do not necessarily state or reflect those of the United States Government or any agency thereof, its contractors or subcontractors. 


\section{Authors}

The authors of this report are Mark Singer and Cabell Hodge of the National Renewable Energy Laboratory (NREL) and Ashley Pennington of the U.S. Department of Energy's Federal Energy Management Program (FEMP).

\section{Acknowledgments}

This report was developed for and sponsored by FEMP with Kendall Kam as the program manager. Additional FEMP reviewers include Hayes Jones, Joanne Lowry, Karen Guerra, and Jay Wrobel.

The authors are indebted to Eliza Hotchkiss, Greg Guibert, Anne Hampson, Sheila Hayter, Marc McConahy, and Margo Melendez for reviewing this work and providing invaluable feedback. They would also like to thank Heidi Blakley and Caitlin Dorsey for their diligence and attention to detail while editing this report. Any remaining errors are the sole responsibility of the authors. 


\section{List of Acronyms}

AFV alternative fuel vehicle

DOE U.S. Department of Energy

FEMP Federal Energy Management Program

NREL National Renewable Energy Laboratory

PEV Plug-in electric vehicle

TRN Technical Resilience Navigator 


\section{Executive Summary}

Federal fleet operations span the diverse geography of the country as the vehicles provide services in support of equally diverse agency missions. Fleets face the potential for disruption of services from natural disasters, infrastructure failures, and human threats. This report reviews some of the hazards, threats, and disruptions that fleets may face, describes an approach to fleet management that incorporates resilience, and provides an overview of fleet resilience considerations. While this report is not comprehensive, it describes considerations for integrating resilience into fleet management organizational priorities.

Fleet resilience seeks to (1) protect fleet operations from small disruptions through a robust infrastructure, (2) maintain fleet operations during moderate disruptions through redundant systems, (3) return the fleet to full operations as quickly as possible after severe disruptions following a recovery plan, and (4) mitigate or minimize damage through resourcefulness. The consequences of disruptive events can be minimized by preemptively safeguarding vehicles, fuel availability, and infrastructure and by providing back-up power to fueling stations. Collaboration and outreach allow the fleet to play a mutually beneficial role in cross-functional energy resilience.

As fleet missions, technology, and risks change over time, plans will need to be revised. The incorporation of resilience into fleet management is an iterative process of prioritizing critical fleet assets and operations, identifying hazards, threats, vulnerabilities, and potential consequences, strategizing efforts to reduce risk, and implementing those strategies. It requires collaborating with internal and external partners as well as accounting for parallel goals, such as petroleum reduction and fleet electrification.

Factoring resilience planning into the fleet management process will lay the groundwork for a more structured approach for fleet managers to proactively address potential disruptions in fleet operations while implementing solutions that enhance resilience. 


\section{Table of Contents}

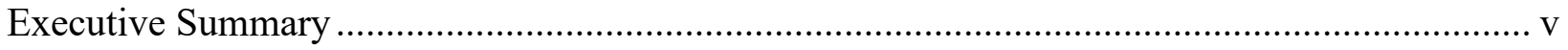

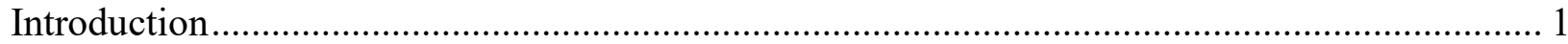

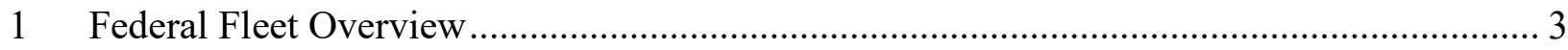

2 Hazards, Threats, and Vulnerabilities to Fleet Operations ................................................ 7

3 Fleet Management Approach Toward Resilience ..................................................... 10

3.1 Incorporating Fleet Management Into Resilience Planning ....................................... 10

3.2 Integrating Fleet Continuity Into Broader Efforts................................................ 13

3.3 Baseline Current Fleet Vehicles and Identify Vulnerabilities.................................... 14

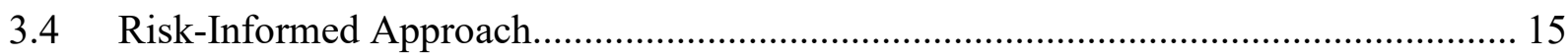

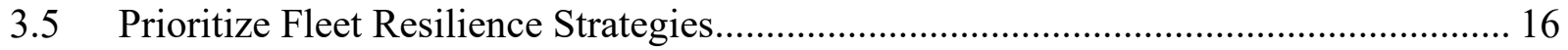

4 Fleet Resilience Improvement Considerations ............................................................... 17

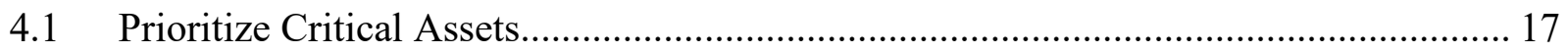

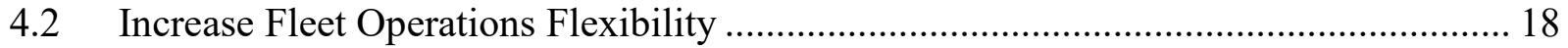

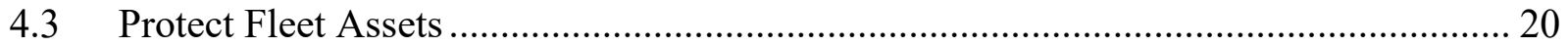

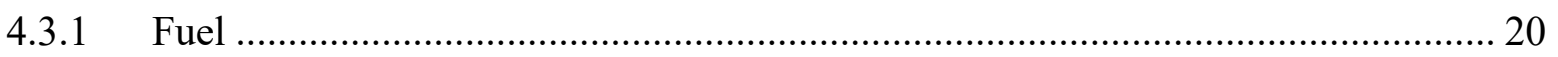

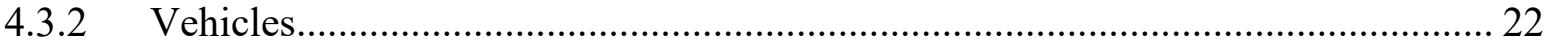

4.3.3 Electricity and Transportation Infrastructure............................................... 23

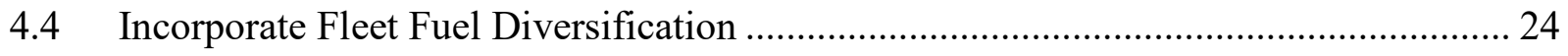

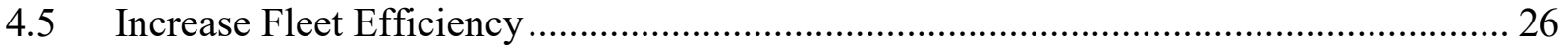

4.6 Increase Transparency by Refining Fleet Data Management ................................... 27

4.7 Collaborate and Communicate With Stakeholders ................................................. 27

4.8 Integrate Fleet Planning in Agency Resilience Efforts .......................................... 28

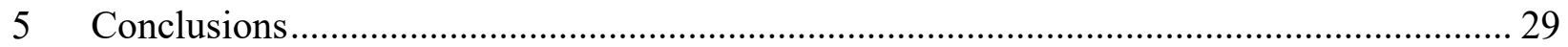

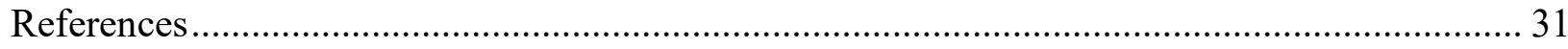




\section{List of Figures}

Figure 1. Colorado flooding in 2013 ................................................................................... 1

Figure 2. 2019 Federal fleet vehicles by agency ..................................................................... 3

Figure 3. Emergency response vehicles by Federal agency …............................................ 4

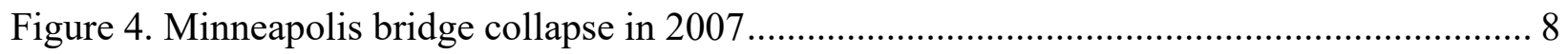

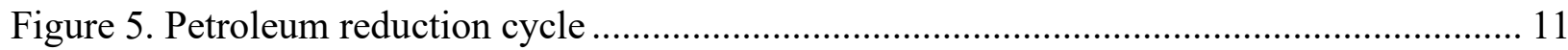

Figure 6. Technical Resilience Navigator framework ........................................................... 12

Figure 7. Federal shuttle routes in DC area ……………..................................................... 19

Figure 8. A truck drives through flood water in New York City after Hurricane Sandy ............. 22

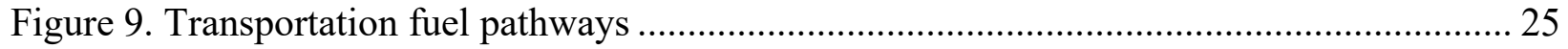

\section{List of Tables}

Table 1. Template for fleet resilience plan ............................................................................ 30 


\section{Introduction}

Fleet resilience faces a host of natural and human hazards, ranging from the adverse effects of climate change to terrorism. Federal fleets are instrumental in achieving an extensive set of missions, including providing critical health services, maintaining $28 \%$ of the land in the United States, and delivering key resources to the nation's armed forces. Despite the obvious impacts to transportation from natural disasters like the one shown in Figure 1, Federal resilience planning often overlooks motor vehicles and focuses on the built environment.

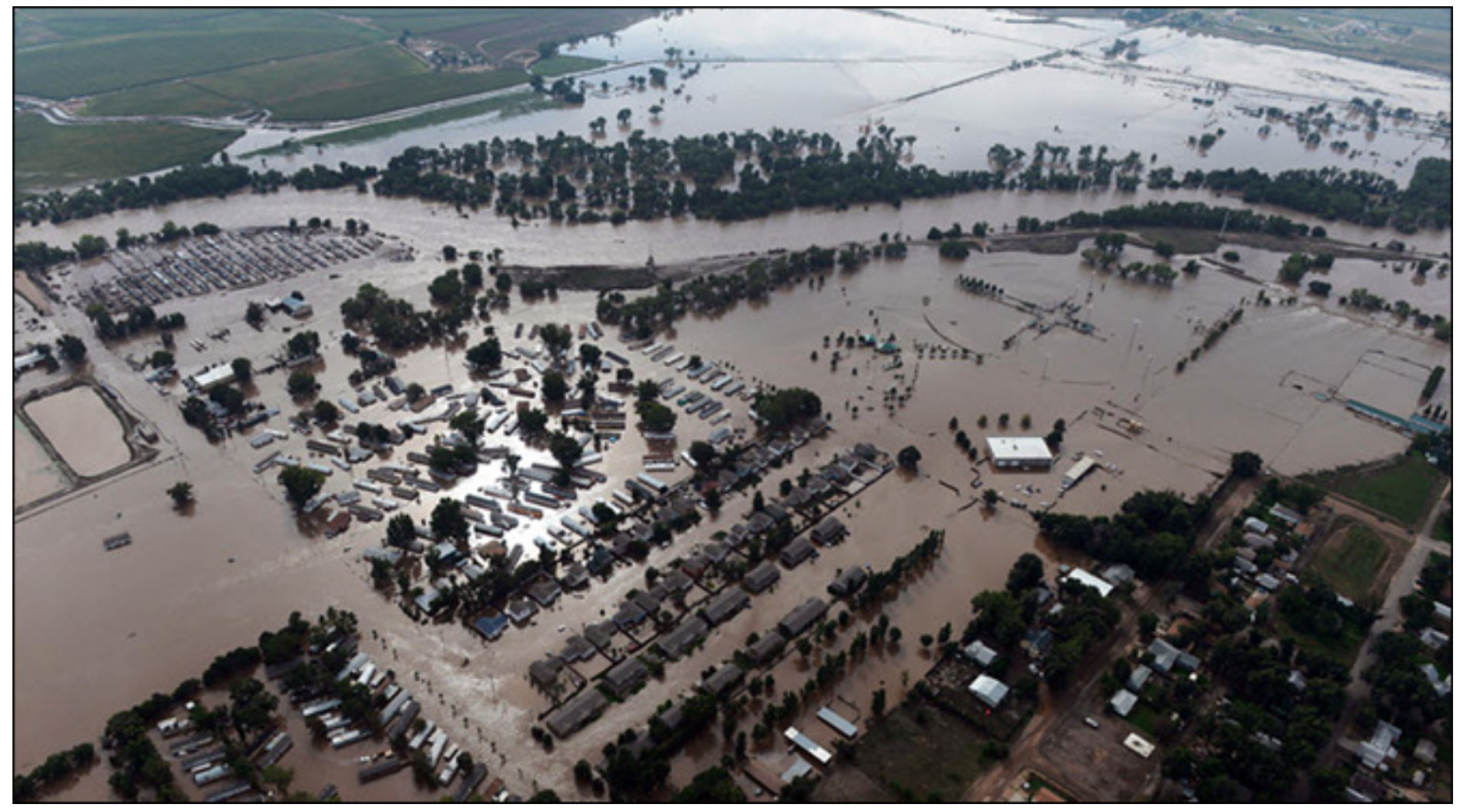

Figure 1. Colorado flooding in $2013^{1}$

Photo from National Weather Service, courtesy of State of Colorado

Fleet resilience aims to incorporate a risk-informed approach to anticipate, prepare for, and withstand changing conditions that would otherwise be detrimental to fleet operations. Focusing on incorporating resilience into fleet planning will protect and maintain fleet operations when inevitable disruptions prohibit normal operations and will aid in returning the fleet to full operations when disruptions cannot be avoided. Fleet resilience is distinct from disaster preparedness by emphasizing proactive strategies. Fleets are an integral instrument of agency missions. Therefore, Federal agency resilience planning should focus on whether employees can continue to meet mission objectives regardless of disruptions rather than simply ensuring that individual vehicles remain available.

This report describes considerations for integrating resilience into fleet management organizational priorities. This document describes considerations for incorporating resilience into

\footnotetext{
${ }^{1}$ National Weather Service, n.d. "Floods in Colorado." https://www.weather.gov/safety/flood-states-co.
} 
organizational plans and is not an action-oriented resource or tool. This document aims to introduce Federal fleet and energy managers to the resilient-efficient-secure nexus and the attributes of resilience such that they are empowered to strengthen the resilience of the fleets that they manage to ensure continuity of operations during disruptions and thus the ability to continually meet mission objectives. Section 1 describes the Federal fleet at a high level; Section 2 explores potential disturbances to fleet operations; Section 3 outlines a continuity planning structure; Section 4 offers strategies to improve continuity; and Section 5 reviews conclusions and steps agencies can take, including a template to complete a plan. 


\section{Federal Fleet Overview}

The U.S. Department of Energy (DOE) Federal Energy Management Program (FEMP) supports non-tactical motor vehicle fleets in efforts to comply with legislative and executive mandates, improve efficiency, reduce petroleum consumption, and promote fleet resilience. The missions of these fleets vary widely including land management, healthcare, training, passenger travel, utility services, and postal delivery. In addition, the Department of Defense and U.S. Coast Guard operate thousands of tactical motor vehicles with military or rescue missions as well as aviation and marine assets. While FEMP's scope is limited to the non-tactical Federal vehicles depicted in Figure 2, the lessons in this report apply in many cases to tactical vehicles and other types of transportation assets.

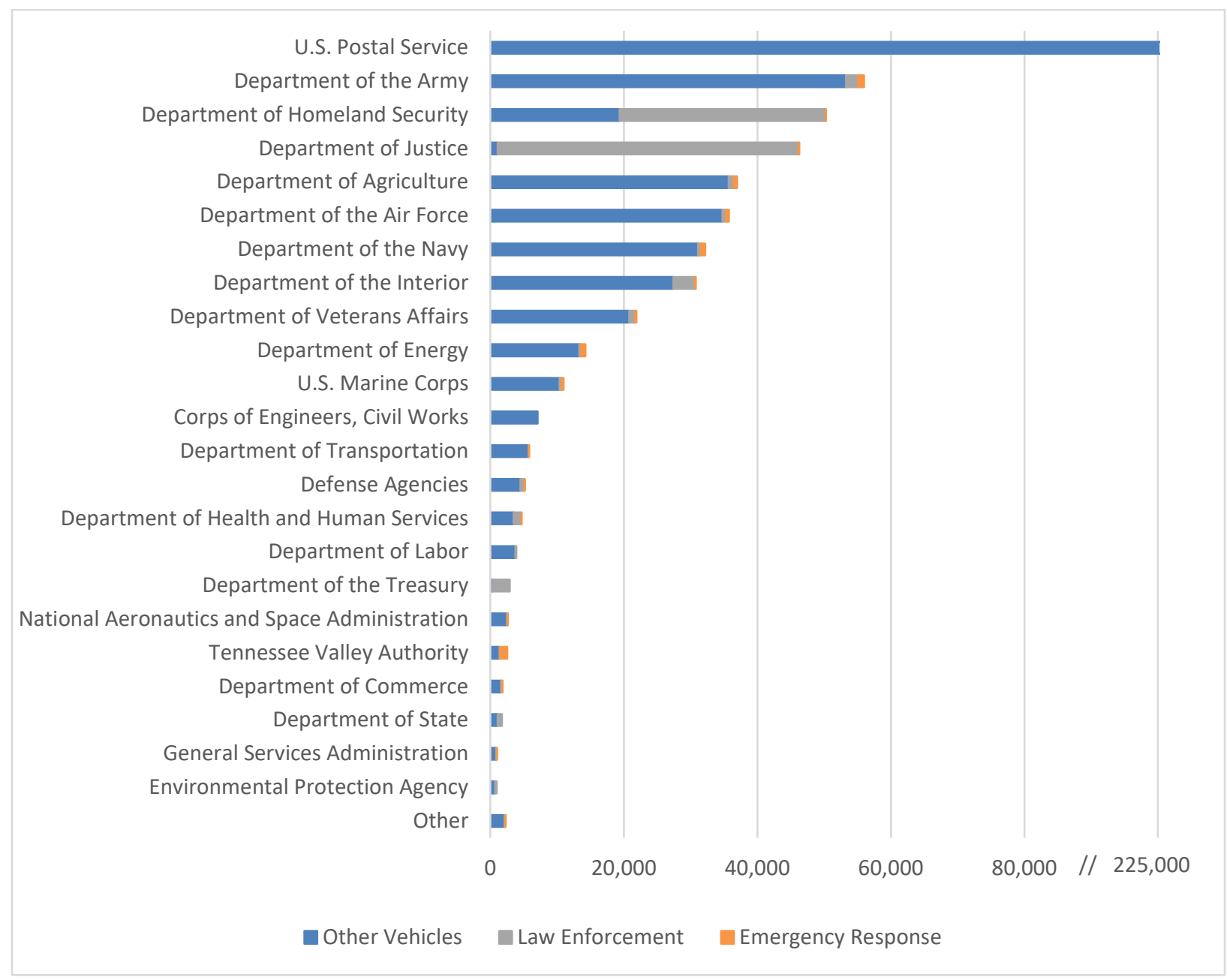

Figure 2. 2019 Federal fleet vehicles by agency

Critical vehicles include the 5,262 Federal fleet vehicles in Figure 3 that were designated as emergency response based on specific characteristics that made typical commercial vehicles unsuitable for their purposes. However, there are other critical vehicles unique to each agency's mission that are not designated as emergency response. 
Though critical vehicles are specific to fleet, critical functions, loads, and missions are defined in FEMP's Technical Resilience Navigator (TRN) as follows ${ }^{2}$ :

- Critical Functions: "The operations and activities required to enable a critical mission (e.g., a data center's critical function is to process data for scientific analysis). Critical functions are enabled by critical loads (e.g., a chiller is a load that provides cooling to allow the data center to meet its critical function)."

- Critical Loads: "The energy or water loads that are required to enable critical functions. These depend on the supply of energy or water and can be impacted by a disruption to these systems."

- Critical Mission: "A mission of such high importance that its incapacitation or destruction would have a severely degrading effort on the ability of the agency to execute the tasks or mission-essential tasks it supports in all operating environments. A critical mission is supported by critical functions, which are enabled by loads (e.g., facilities, systems, equipment, and resources)."

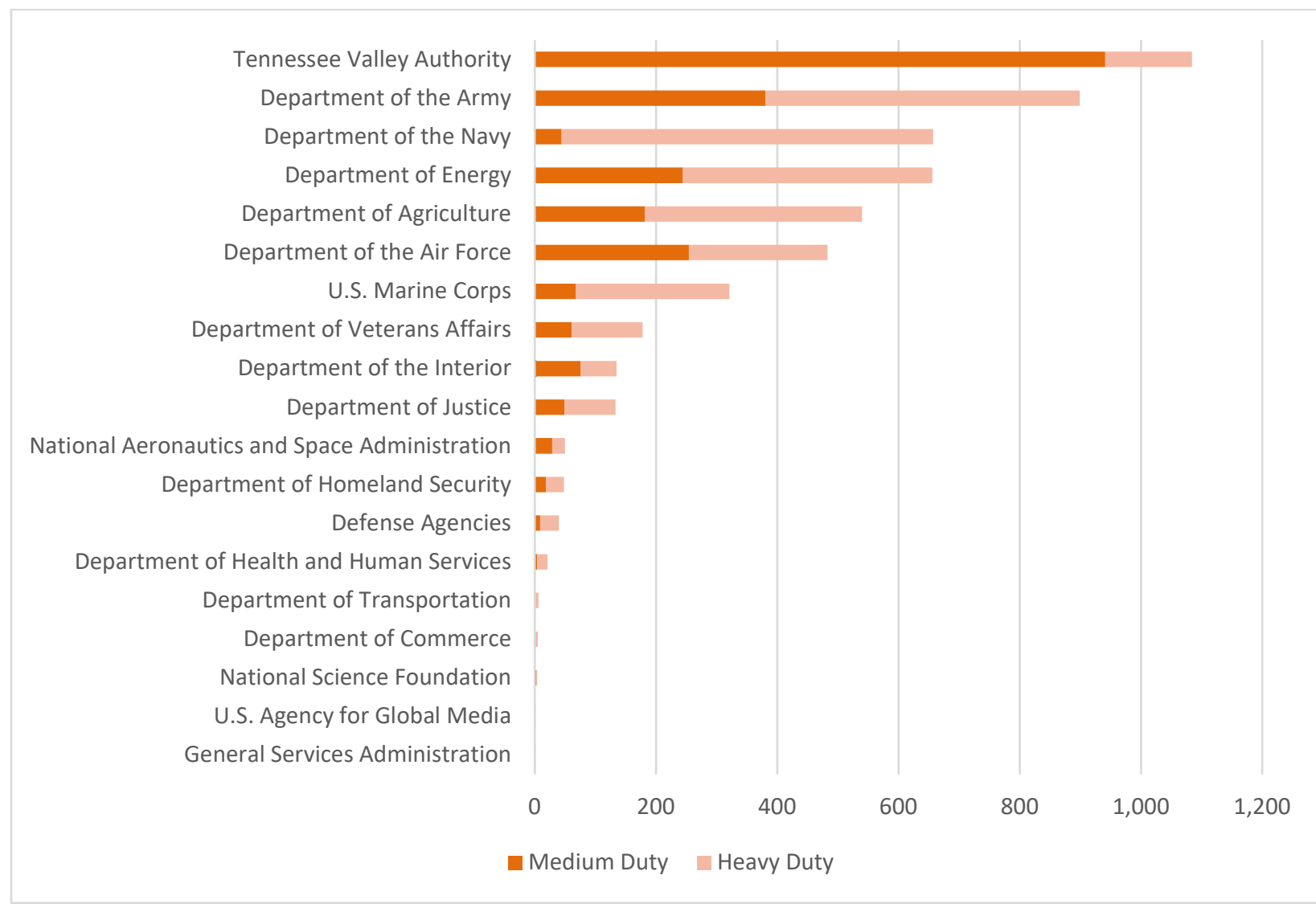

Figure 3. Emergency response vehicles by Federal agency

\footnotetext{
${ }^{2}$ TRN. "Glossary.” https://trn.pnnl.gov/glossary.
} 
Managing fleet resilience is a broad exercise for the Federal fleet. Fleets are comprised of vehicles ranging from small light-duty sedans to heavy-duty trucks providing diverse and highly specific capabilities. Fleet missions vary by type and scale. Passenger transport ranges from a single driver in a small car on a closed campus to the transport of dozens of passengers on an interstate bus. Type and scale of cargo transport vary similarly. Many fleets support campus settings such as military installations or hospital and office complexes that use vehicles to serve infrastructure maintenance roles including mobile workstations and transport of equipment and machinery. Other fleets play a regional role where vehicles cover a broad geography to carry out inspections, provide medical services to veterans, or conduct patrols. These roles have different requirements to maintain operations at the time of a crisis, and will have different critical functions and critical missions, but developing a resilience plan like those outlined in the TRN tool will be critical to successfully maintain continuity of operations.

The Federal fleet often plays an important role during crises because of its missions and ability to deploy across the country. As a prominent example, the Federal Emergency Management Agency (FEMA) created the National Response Framework ${ }^{3}$ and Federal Interagency Operational Plans ${ }^{4}$ to define roles that agencies should play in the event of an emergency. The framework includes annexes for emergencies affecting transportation ${ }^{5}$ and energy. ${ }^{6}$ Fleets should be prepared to support these emergency specific missions. The 15 agencies with defined response roles during these events include:

- Department of Agriculture

- Department of Commerce

- Department of Defense

- Department of Energy

- Department of Homeland Security

- Department of the Interior

- Department of Justice

- Department of Labor

- Department of State

- Department of Transportation

\footnotetext{
${ }^{3}$ FEMA. "National Response Framework.” https://www.fema.gov/emergency-managers/nationalpreparedness/frameworks/response.

${ }^{4}$ FEMA. "Federal Interagency Operational Plans." https://www.fema.gov/emergency-managers/nationalpreparedness/frameworks/federal-interagency-operational-plans.

${ }^{5}$ FEMA. Emergency Support Function \#1 - Transportation Annex. https://www.fema.gov/sites/default/files/202007/fema_ESF 1 Transportation.pdf.

${ }^{6}$ FEMA. Emergency Support Function \#12 - Energy Annex. https://www.fema.gov/sites/default/files/202007/fema_ESF_12 Energy-Annex.pdf.
} 
- Environmental Protection Agency

- General Services Administration

- Nuclear Regulatory Commission

- Tennessee Valley Authority

- U.S. Postal Service. 


\section{Hazards, Threats, and Vulnerabilities to Fleet Operations}

Federal fleet vulnerability to hazards and threats largely depends on mission scope and the physical and geographic setting of the fleet. The resilient-efficient-secure nexus leverages the co-benefits of efficiency, reliability, and optimization solutions in resilience planning. The nexus feeds into FEMP's resilience framework providing an organizational process that enables the identification of critical energy and water systems, assessment of vulnerabilities, and application of a risk informed approach in developing and prioritizing resilience solutions. Resilience planning using a risk-informed approach accounts for points of disruption. FEMP's resilience framework provides organizational processes that enable the identification of critical systems, assessment of vulnerabilities, and application of a risk-informed approach in developing and prioritizing resilience solutions. While FEMP's Technical Resilience Navigator (TRN) ${ }^{7}$ focuses on energy and water resilience planning the steps outlined can be leveraged during the process of conceptualizing fleet resilience planning. In the TRN definitions for disruptions to critical loads and systems are as follows:

- 'Hazards: A natural or accident-based cause with the potential to disrupt a site's mission(s). Examples of natural hazards include earthquakes, storms, and wildfires. Examples of accident-based hazards include dam failures, train derailments, and industrial accidents.

- Threats: An adverse event associated with malicious intent to create negative consequences. Sometimes the term threat refers to the likelihood of that threat being realized as an event. Threat is quantified as the probability of a threat being realized.

- Vulnerabilities: The probability of a consequence occurring given that the hazard or threat has been realized. It is the probability that safeguards or protections intended to mitigate the hazard or threat fail."

\footnotetext{
${ }^{7}$ TRN. Home Page. https://trn.pnnl.gov.
} 


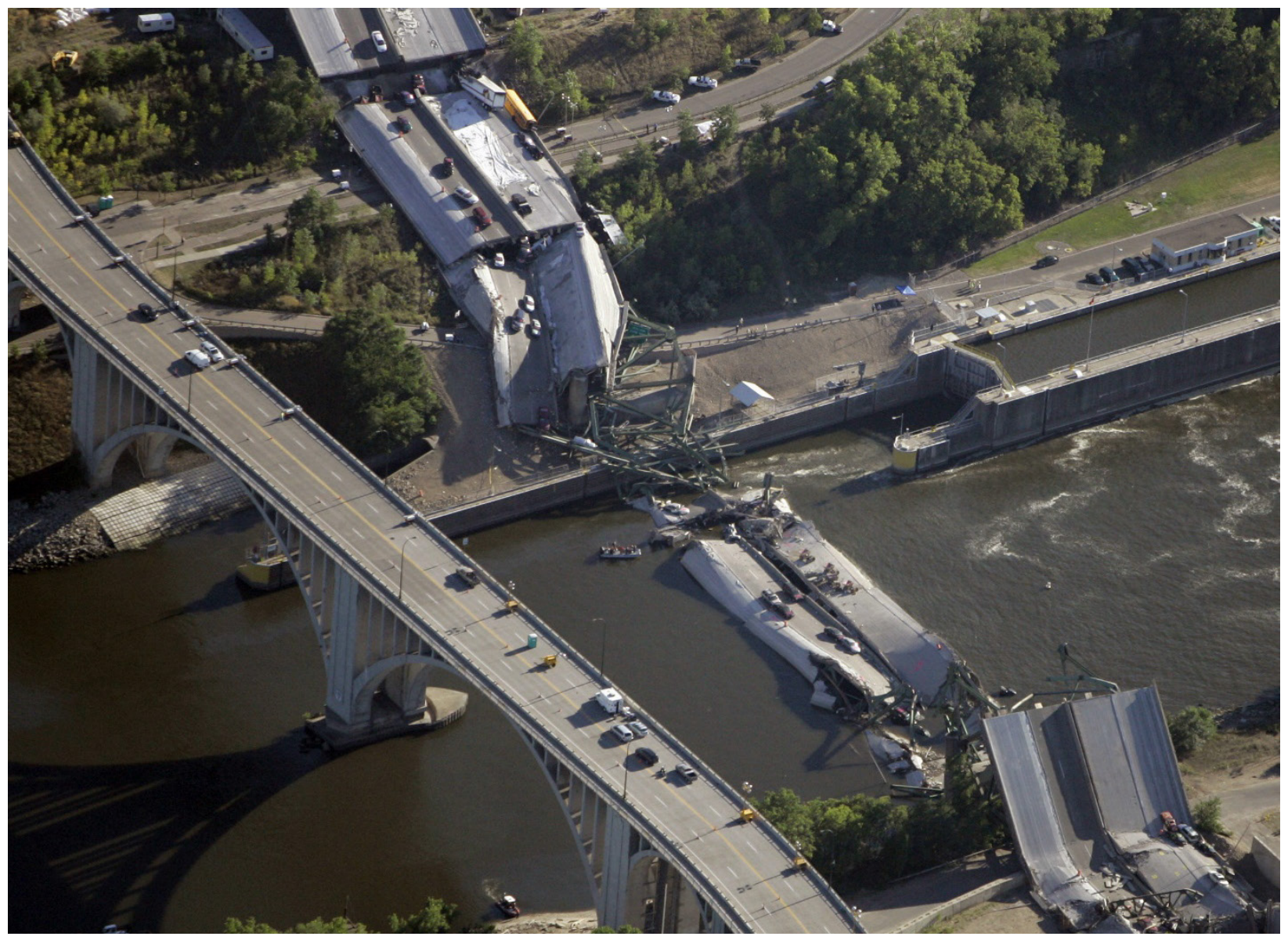

Figure 4. Minneapolis bridge collapse in $2007^{8}$

Photo from Morry Gash, Associated Press

Hazards, threats, and vulnerabilities can lead to disruptions of fleet operations (Figure 4). DOE has detailed ${ }^{9}$ how natural hazards can affect fueling and transportation infrastructure. The primary end effect of natural hazards is structural damage to infrastructure from flooding, wind, fires, freezing, and ground movement; vehicles can be disabled as well. Flooding can be related to heavy rains, hurricanes, tsunamis, and derechos. Wind damage results from tornadoes, hurricanes, and derechos. Fires may result directly from wildfires, lightning strikes, or as a secondary effect from damaged infrastructure. Ground movement or instability may result from earthquakes or other seismic events, flooding, erosion, or severe temperature events. DOE has detailed the potential severity of impacts of natural hazards on energy infrastructure by geographic region. ${ }^{10}$

\footnotetext{
${ }^{8}$ Schaper, David. 2017. "10 years After Bridge Collapse, America Is Still Crumbling."

https://www.nprillinois.org/post/10-years-after-bridge-collapse-america-still-crumbling\#stream/0.

${ }^{9}$ AOC Petroleum Support Services, Inc. 2014. United States Fuel Resiliency Volume III.

https://www.energy.gov/sites/prod/files/2015/04/f22/QER\%20Analysis\%20-

\%20United\%20States\%20Fuel\%20Resiliency\%20Volume\%20III.pdf.

${ }^{10}$ U.S. Department of Energy Office of Energy Policy and Systems Analysis. 2015. Climate Change and the U.S. Energy Sector: Regional Vulnerabilities and Resilience Solutions.
} 
Fleet operations are affected when infrastructure and vehicles are inaccessible or inoperable due to physical damage or are unable to perform for the duration of a continued outage. For instance, many of these disruptive events can cause the loss of electric grid power, which can render infrastructure, particularly fueling stations, unusable due to lack of power for pumping fuel.

Fleet operations may also be affected by mission-related changes. Federal agencies may be reorganized or responsibilities added by statute. Alternatively, external circumstances might require additional tasks or increases in specific responsibilities. Using a structured fleet resilience management approach helps ensure that technological, operational, and institutional solutions are considered.

https:/www.energy.gov/sites/prod/files/2015/10/f27/Regional_Climate_Vulnerabilities_and_Resilience_Solutions $\underline{0 . p d f}$. 


\section{Fleet Management Approach Toward Resilience}

Successful fleet continuity of operations is not an end state; it is incorporated into management processes to ensure resilient and secure fleet operations. Crises and disruptive events often do not respect organizational boundaries, and fleets do not operate in a vacuum. To prepare an organization to effectively respond to emergency or crisis events through the implementation of resilience enhancing solutions often requires engaging stakeholders outside of the traditional organizational structure. This may include engaging cross-function roles within an organization such as communication between fleet management and facilities management as well as local and regional partners with aligned interests such as utilities, state and local governments, and private industry. It is important to create these cross-organization connections in advance of events rather than once an event occurs. ${ }^{11}$

Implementing this inclusive approach would enable fleet managers to collect information around critical energy and fleet infrastructure. Within FEMP there are several existing tools and resources that can support fleet managers in understanding baseline energy and water requirements associated with fleet continuity such as:

- 50001 Ready Navigator ${ }^{12}$ : online application that provides step-by-step guidance for implementing and maintaining an energy management system in conformance with the ISO 50001 Energy Management System Standard.

- Technical Resilience Navigator (TRN) ${ }^{13}$ : online tool that provides a systematic approach to identifying energy and water resiliency gaps and developing and prioritizing solutions that reduce risk.

Both of these tools provide mechanisms to collect and analyze baseline energy and water loads that can be used in the identification and understanding of key fleet operational requirements in relation to continuity planning.

\subsection{Incorporating Fleet Management Into Resilience Planning}

The cycle of fleet management outlined in Federal Best Practices: Core Principles of Sustainable Fleet Management ${ }^{14}$ includes the phases to plan, collect, strategize, and implement leading back to the next cycle of the process (Figure 5). The planning phase involves setting high-level goals aligning with fleet regulatory mandates. The next steps involve collecting specific fleet data and strategizing specific actions to achieve the set goals. Finally, the implementation stage involves carrying out these strategies through fleet operations.

\footnotetext{
${ }^{11}$ Hotchkiss, Eliza, and Alex Dane. 2019. Resilience Roadmap: A Collaborative Approach to Multi-Jurisdictional Resilience Planning. Golden, CO: NREL. NREL/TP-6A20-73509. https://www.nrel.gov/docs/fy19osti/73509.pdf.

1250001 Ready Navigator. Home Page. https://navigator.lbl.gov/.

13 TRN. Home Page. https://trn.pnnl.gov/.

${ }^{14}$ EERE. 2020. Federal Best Practices: Core Principles of Sustainable Fleet Management. https:/www.energy.gov/sites/prod/files/2020/11/f80/federal-best-practices-sustainable-fleet.pdf.
} 


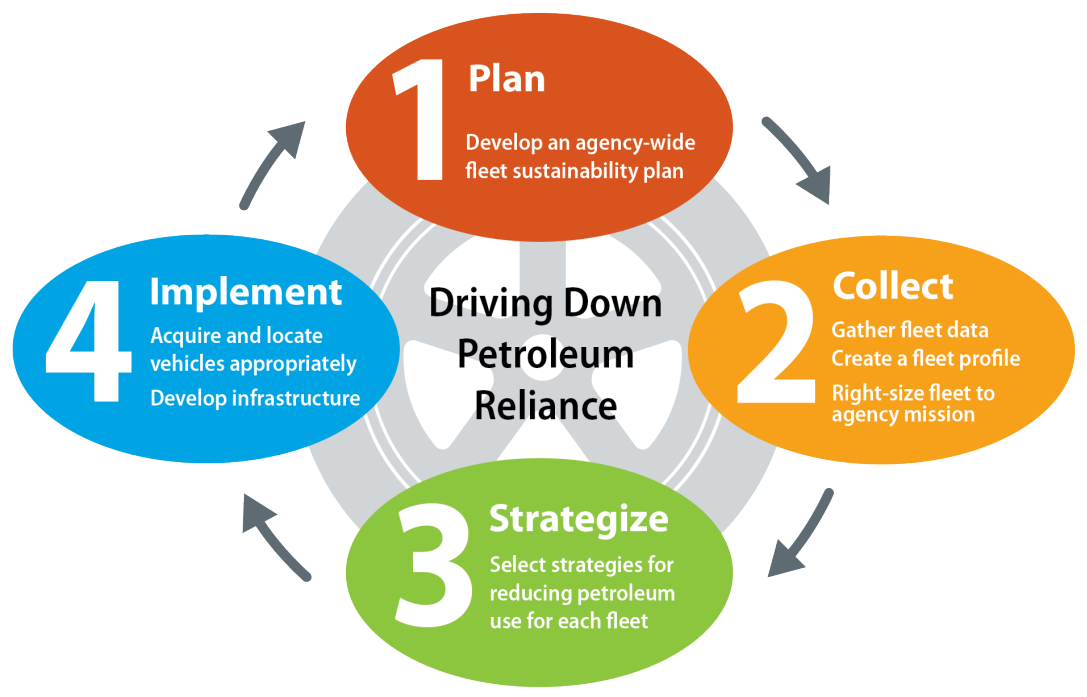

Figure 5. Petroleum reduction cycle

Fleet managers can draw from the process outlined above to develop an organizational approach to resilience planning. Various federal organizations have outlined similar cycles for management for applications in fleets and beyond. The U.S. Forest Service, ${ }^{15}$ Federal Highway Administration, ${ }^{16}$ and DOE FEMP ${ }^{17}$ have documented processes that generally follow an approach comprised of steps to:

1. Define a group of stakeholders and the appropriate scope for the assessment

2. Gather data and evaluate baseline operations regarding critical functions

3. Assess risks through analysis of hazards, threats, vulnerabilities, and consequences

4. Identify gaps and evaluate strategies to address risks

5. Implement appropriate strategies and prioritize solutions to mitigate risk

6. Monitor and evaluate strategy and solution effectiveness.

FEMP has developed the TRN to guide agencies through the resilience planning process for site energy and water resilience, using a risk-informed approach. ${ }^{18}$ The TRN lays out a planning process (Figure 6) leading the user through six planning modules: site-level planning, baseline development, risk assessment, solution development, solution prioritization, and roadmap to action. These modules are parsed into various actions that work together to build a resilience framework specific to the user's needs. The process begins by creating a core resilience planning team, gathering relevant information, and identifying priorities, scope, boundaries, and critical

\footnotetext{
${ }^{15}$ U.S. Department of Transportation. "U.S. Forest Service Transportation Resiliency Guidebook: Addressing Climate Change Impacts on U.S. Forest Service Transportation Assets.” https://www.volpe.dot.gov/FS-

Transportation-Resiliency-Guidebook.

${ }^{16}$ U.S. Department of Transportation. Vulnerability Assessment and Adaptation Framework, $3^{\text {rd }}$ Edition. https:/www.fhwa.dot.gov/environment/sustainability/resilience/adaptation framework/.

${ }^{17}$ TRN. Home Page. https://trn.pnnl.gov/.

18 TRN. Home Page. https://trn.pnnl.gov/.
} 
functions for the site assessment. Then during baseline development, the baseline documentation is reviewed spawning the establishment of energy and water requirements and baseline conditions used in future comparison. The risk assessment portion of the process begins exposing gaps between baseline conditions and a more resilient state by characterizing critical loads, identifying and assessing hazards threats and vulnerabilities, and summarizing risk factors that should be included in the solution development phase. These recorded resilience gaps are reviewed and analyzed to enable brainstorming and development of comprehensive solutions that can enhance resilience. Finally, solution prioritization provides a method for assessing the potential benefits and costs of identified resilience solutions to enable solution ranking for implementation. While the tool focuses on critical energy and water loads at sites, the concepts presented in the TRN can be translated and implemented within fleet resilience planning efforts. Vehicles are key aspects of energy systems and mission sustainment. Stepping meticulously through the resilience planning process helps to ensure the ability of the fleet to anticipate, withstand, responded to, and rapidly recover from a disruptive event.

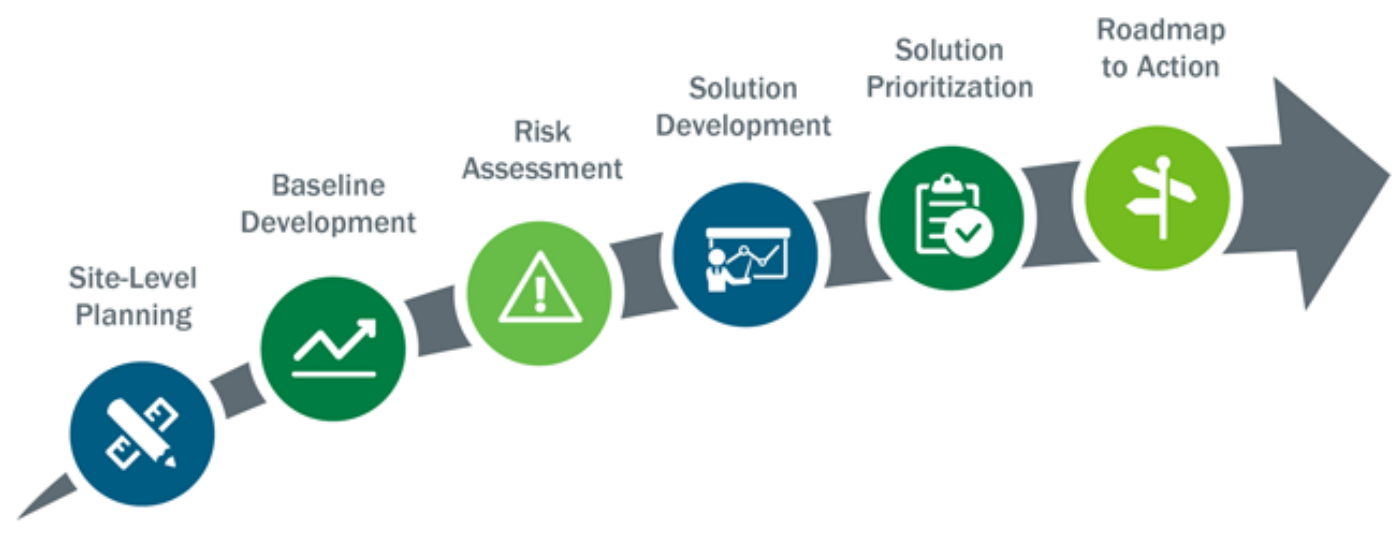

Figure 6. Technical Resilience Navigator framework ${ }^{19}$

Illustration from https://trn.pnnl.gov/about

The 50001 Ready Program is a FEMP effort that provides an avenue to integrate fleet continuity into overall strategic energy planning. ${ }^{20} 50001$ Ready is a strategic approach to energy

management that provides tools to personnel with overlapping interests and tangential job duties to create a culture of continuous improvement. With sustained effort, the tools within the 50001 Ready Navigator can inform and help build a unified, resilient energy program. ${ }^{21}$

Existing Federal fleet management efforts can be leveraged to meet the parallel objectives of the TRN, 50001 Ready, and fleet continuity without creating large additional management burdens.

\footnotetext{
19 TRN. "About the TRN." https://trn.pnnl.gov/about.

${ }^{20}$ DOE. "50001 Ready.” https://navigator.lbl.gov/.

${ }^{21}$ Wrobel, Jay, Olwen Huxley, Soudeh Motamedi, Brad Gustafson, Joan Hughes, Michael Socks, and Clay Hoover. 2020. “50001 Ways to Save Energy and Support Mission” Energy Exchange 2020.
} 
FEMP is available to support efforts to incorporate fleet continuity into overall energy resilience efforts. This could include developing fleet baselines using data in the Federal Automotive Statistical Tool ${ }^{22}$ and Fleet Sustainability Dashboard, ${ }^{23}$ identifying risks based on location, and proposing solutions to improve resilience.

\subsection{Integrating Fleet Continuity Into Broader Efforts}

While Federal fleet managers may have opportunities to lead cross-function and interorganization continuity efforts, this document is intended to help fleet managers understand the role they can play in support of these larger efforts as well as the steps they can take internally to improve the resilience of their specific fleet. Stakeholder engagement will be a large component of resilience planning, as illustrated in the TRN and other efforts.

A primary first step in the process is understanding the key stakeholders across different organizations, which for any given geography could include utility providers, local and tribal governments, state governments, and other federal agencies. Federal fleet managers may have an opportunity to support resilience efforts undertaken by these organizations. Awareness of, and engagement with, these contacts will benefit Federal fleet managers as they develop internal fleet specific resilience efforts. The lessons learned through disaster recovery efforts at the community and agency level may serve as a good starting point for creating a resilience structure for fleets.

The American Association of State Highway and Transportation Officials ${ }^{24}$ (AASHTO) has developed a resource that can help fleet managers identify state level continuity efforts. The AASHTO online tool allows users to select a state to view its existing planning resources focused primarily on transportation continuity. Some of these efforts include existing coordination efforts with local and tribal governments. The National Association of State Energy Officials (NASEO) coordinates the Initiative for Resiliency in Energy through Vehicles ${ }^{25}$ (iREV) which provides cross-organization coordination of alternative fuel vehicles to support fleet resilience specifically. The iREV is an additional resource for Federal fleet managers to understand existing regional activities aligned with Federal fleet continuity.

The Federal Fleet INTERFUEL ${ }^{26}$ working group provides a forum for fleet managers to engage on a range of topics specifically affecting federal fleet operations. Fleets may use this forum as an opportunity to engage in cross-agency coordination or information sharing related to fleet continuity.

${ }^{22}$ GSA. "Federal Automotive Statistical Tool." https://fastweb.inl.gov/.

${ }^{23}$ EERE. "Fleet Sustainability Dashboard." https://federalfleets.energy.gov/FleetDASH/.

${ }^{24}$ Center for Environmental Excellence. "Resilient and Sustainable Transportation Systems Technical Assistance

Program." https://environment.transportation.org/center/rsts/state by_state_map.aspx.

${ }^{25}$ NASEO. "iRev-Initiative for Resiliency in Energy through Vehicles." https://www.naseo.org/irev.

${ }^{26}$ EERE. "Interagency Committee on Alternative Fuels and Low Emission Vehicles (INTERFUEL) Working Group." https://www.energy.gov/eere/femp/interagency-committee-alternative-fuels-and-low-emission-vehiclesinterfuel-working-group. 
Coordination with local utilities is key to fleet continuity. The DOE FEMP Federal Utility Partnership Working Group ${ }^{27}$ (FUPWG) is an existing structure of Federal agency engagement with the utilities providing service across the country. This network of utilities is a useful resource for identifying stakeholders for continuity planning by fleet region.

Fleet managers likely already work closely with facility managers. Risks to a fleet are often the same as the risks faced by the rest of a facility, although consequences likely vary. By integrating fleet continuity planning with overall site resilience efforts, fleet managers can capitalize on existing work to identify hazards and threats. For example, there is a module in the TRN focused on risk assessment and ideas from this module can be implemented in fleet resilience planning.

\subsection{Baseline Current Fleet Vehicles and Identify Vulnerabilities}

Fleet managers can focus fleet resilience efforts on those missions most needed at the time of an emergency using data on prioritized mission requirements and typical fleet operations. Sites may or may not have existing data on prioritized missions and the fleets that support them. Federal fleet managers are required to submit fleet operations data at the end of the year to the Federal Automotive Statistical Tool (FAST) ${ }^{28}$ and are required to collect and manage fleet data in a fleet management information system (FMIS). ${ }^{29}$ Many fleet managers conduct periodic vehicle allocation methodologies ${ }^{30}$ to understand how fleets can efficiently be aligned to mission requirements. Finally, fleets have fuel transaction data available in FleetDASH. ${ }^{31}$ Fleet managers can leverage these resources to develop resilience focused fleet management baselines.

Specific fleet requirements will vary, but generally the key data points include:

- Vehicle mission

- Vehicle locations

- Vehicle types (sedan, pick-up truck, bus, etc.)

- Vehicle fuel types (including all fuel types a vehicle can operate on)

- Vehicle mission (including emergency response and law enforcement roles)

- Fuel use summarized by vehicle and location

- Fuel use summarized by fuel station

- Vehicle miles traveled

- Fuel station locations (both fleet managed stations and regularly used public stations)

\footnotetext{
${ }^{27}$ EERE. "Federal and Utility Collaboration.” https:/www.energy.gov/eere/femp/federal-utility-partnershipworking-group.

${ }^{28}$ GSA FMR Part 102.34.335

${ }^{29}$ GSA FMR Part 102.34.340

${ }^{30}$ GSA FMR Bulletin B-43

${ }^{31}$ EERE. "Fleet Sustainability Dashboard." https://federalfleets.energy.gov/FleetDASH/.
} 
- Key support facilities such as maintenance and parking garages.

Additionally, baselines may incorporate seasonal or other mission variations in fleet activity that may influence fleet requirements depending on when an interruption in normal activity occurs. Beyond these utilization statistics baseline efforts may include any internal fleet guidance that may affect operating behavior such as fleet fueling policies that dictate when a vehicle should regularly be fueled or any restrictions on how vehicles are used.

Combined, this information allows fleet managers to understand and communicate both (1) the requirements to meet mission objectives at the time of emergency and (2) the status of available assets that may benefit partners outside the fleet engaged in broader resilience efforts.

Baseline data helps to answer questions such as:

- Where are there concentrations of specific vehicle types by critical mission function?

- How much fuel is required by vehicle type at specific locations?

- Which fuel stations are critical for fleet operations, and which locations have multiple fueling options?

- If an event were to occur and additional fuel were unavailable, how long could the fleet perform its mission?

- What alternatives to fleet vehicles can agencies employ to complete critical missions?

Beyond the assets under their purview, fleet managers can play a role in understanding the key infrastructure the fleet relies on for stable operations in their region. This infrastructure may include but is not limited to transportation infrastructure (e.g., roads, bridges, tunnels, etc.), electric vehicle supply equipment, and electric grid infrastructure (e.g., power lines and transformers). Fleets using this infrastructure are in a unique position to understand their operating level and importance. While fleet managers may not have direct operational control of infrastructure, they may be able help advocate for maintenance and improved reliability.

\subsection{Risk-Informed Approach}

After assessing the stakeholders, baseline and scope, fleet resilience plans should take a riskinformed approach to brainstorm and prioritize solutions like the TRN does for energy and water resources. Although the TRN does not include fleets, the tool's principles can be applied in the fleet setting to address potential impacts on fueling capability, electricity and transportation infrastructure, and vehicle function. Not all risks are equivalent. Short term disruptions to noncritical operations may be acceptable while long term disruptions to critical operations are not acceptable. A detailed risk assessment allows agencies to identify vulnerabilities and appropriate strategies. The TRN provides a framework to determine the relative magnitude of risk that agencies may face. 
The TRN quantifies strategy impacts and costs, and it includes organization-specific decision criteria. Impact can be measured by the portion of the quantified risk that can be reduced through a particular strategy. Strategy cost considerations should include both initial implementation and annual maintenance costs. Organization decision criteria may differ by site but could include ease of implementation, alignment with existing fleet efforts or policies, and urgency of the potential risk. Using a structured approach to prioritizing efforts will allow fleets to create the greatest fleet resilience impact.

\subsection{Prioritize Fleet Resilience Strategies}

A risk-informed approach to risks, solutions, and strategies leads to the necessary task of prioritizing these resilience strategies for the fleet. Once fleet managers have implemented a riskinformed approach and identified solutions, fleet managers prioritize those strategies for their respective fleets based on risk reduction or other weighting factors. This requires balancing the feasibility of the strategies and the degree to which they will improve fleet resilience.

Prioritization can include a screening step where strategies may be excluded from detailed analysis if the strategy involves extremely high costs, relies on resources beyond organization control, or is technically not feasible. These excluded strategies should be retained as future possibilities should situations change that affect these determinations. 


\section{Fleet Resilience Improvement Considerations}

The overarching intent of fleet resilience planning is to (1) protect fleet operations from small disruptions through a robust infrastructure, (2) maintain fleet operations during moderate disruptions through redundant systems, (3) return the fleet to full operations as quickly as possible after severe disruptions following a recovery plan, and (4) mitigate or minimize damage through resourcefulness. The considerations mentioned in section 3.3 are areas in which fleet managers can tailor their resilience planning to best suit the needs of their fleet. Upon doing so, the following primary considerations will aid in formulation of resilience plan that can be maintained throughout the process to provide maximum resilience for the fleet.

Primary considerations include:

- Prioritizing critical assets

- Increasing fleet operations flexibility

- Protecting fleet assets, including fuel, vehicles, and infrastructure

- Incorporating fleet fuel diversification

- Increasing fleet efficiency

- Increasing transparency by refining fleet data management

- Collaborating and communicating with stakeholders

- Integrating fleet planning in agency resilience efforts.

These considerations provide broad benefits that improve fleet continuity and resilience.

Prioritizing these considerations can best be accomplished through site specific assessments of risk, expected impacts, and strategy costs. The TRN provides a detailed process for conducting similar assessments for energy and water loads at sites and may serve as a blueprint for fleet assessments.

\subsection{Prioritize Critical Assets}

Assets should be prioritized based on mission criticality and lack of alternative means to complete that mission. Key fleet assets should be designated within agency resilience planning efforts and prioritized for diversifying their fuel sources as appropriate such as using dual-fuel vehicles, physically securing vehicles in locations protected from hazards, determining level of use by capturing real-time data on those assets through telematics or other means, and accounting for likely changes during disruptive events. Asset prioritization should extend beyond vehicles, to fueling centers, parking structures, and transportation structures. For example, if high priority vehicles are dependent on insecure fueling centers, then fleets can improve resilience by installing their own fueling equipment. 


\subsection{Increase Fleet Operations Flexibility}

Increasing fleet flexibility involves seeking alternatives to specific fleet vehicles to meet mission requirements and reallocation of fleet assets to areas of need. This pertains to employees commuting to worksites in addition to using fleet vehicles once on site. To successfully increase fleet operational flexibility and resilience, fleet managers should identify key stakeholders who would benefit from improved resilience. For instance, managing a fleet of pooled vehicles rather than assigning specific vehicles to individuals or organizations allows fleet personnel to use any of an available set of operable vehicles rather than being constrained to a specific vehicle that may become inoperable or inaccessible in an emergency. However, the individuals and organizations within the fleet requiring the vehicles must be willing to share those vehicles in a way that both increases resilience and meets their mission requirements. A further extension may be coordination with other agency fleets that operate in the same region.

Identifying existing transportation modes outside of the fleet can improve continuity. This may include public transportation or transportation network companies (TNC) for passenger transport. Coordination with other federal agencies and regional organizations can result in benefits to all parties. For example, FEMP worked with Federal fleets to develop an online resource identifying federal agency shuttle services operating in the Washington, DC area. ${ }^{32}$ The online resource provides visibility into disparate shuttle services that have the potential to benefit all agency personnel (Figure 7).

32 EERE. "Federal Fleet Shuttle Stops around Washington, D.C.” https://www.energy.gov/eere/femp/federal-fleetshuttle-stops-around-washington-dc. 


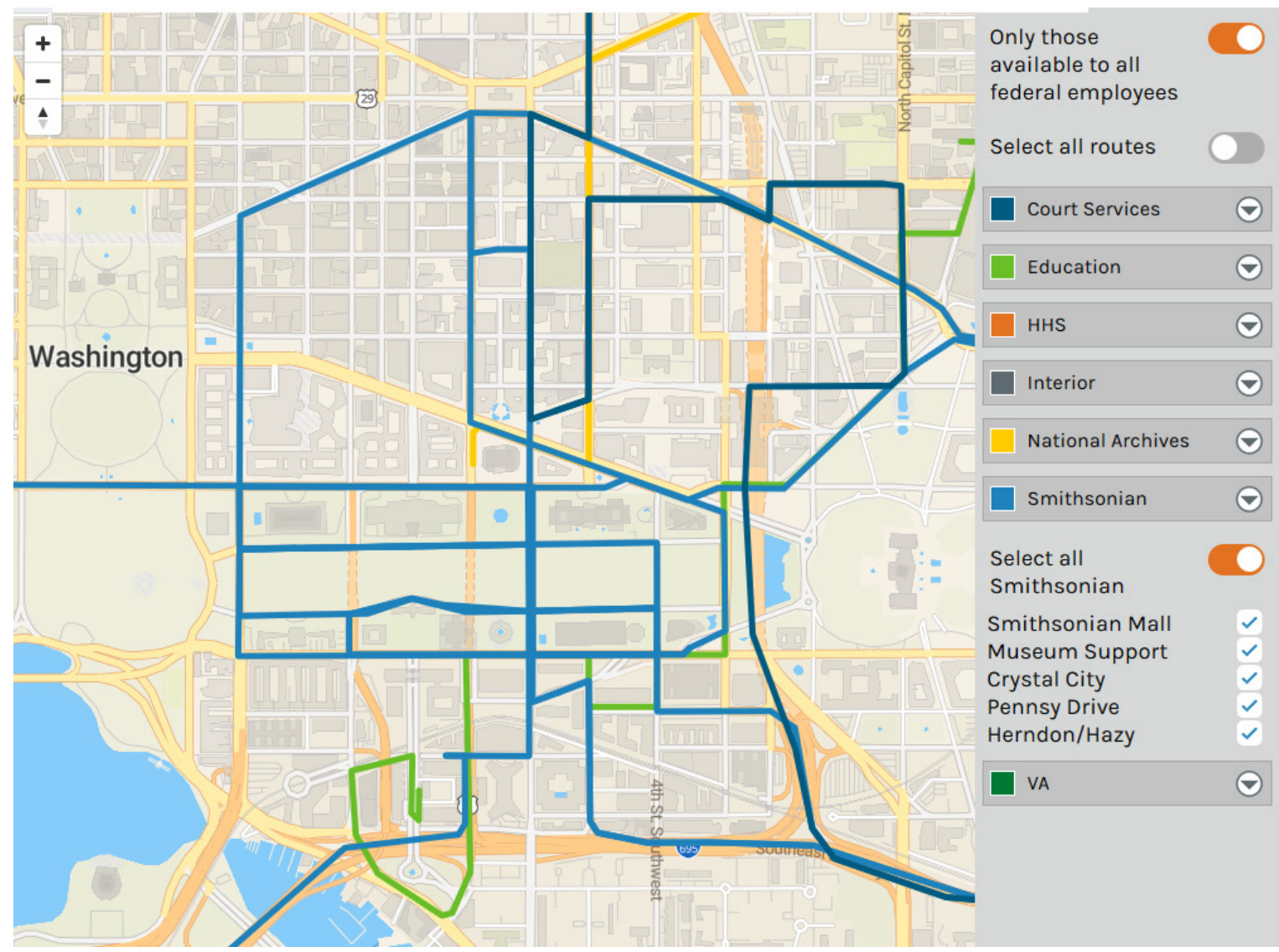

Figure 7. Federal shuttle routes in DC area

Illustration from https://www.energy.gov/eere/femp/federal-fleet-shuttle-stops-around-washington-dc

If employees need to access the office or other worksite, resilience plans should consider how to maintain access to the work location in an emergency and how to address disruptions to roadways and other transportation infrastructure. Offsite infrastructure is generally outside of the fleet manager's control, but they may be able to utilize a risk-informed approach to identify alternative routes. Resilience plans can designate a secondary location for convening in the case that the primary location becomes unavailable, in which case the fleet manager may be responsible for vehicle access at the second location.

In many instances, agencies can meet mission requirements with no vehicles. For example, healthcare response is a critical mission, but alternative provider contractors can lessen the priority of this mission and others for the agency's specific fleet vehicles. The country's response to COVID-19 resulted in many industries finding it possible for employees to productively work from home. Industries across the country experienced varying declines of transportation needs. Some sectors saw significant declines of greater than $50 \%$ while others were forced to continue driving as before. ${ }^{33}$ This uniquely challenging time provides fleets an opportunity to consider

\footnotetext{
${ }^{33}$ Akhtar, Ali. 2020. "4 Ways Reopening Has Changed U.S. Commercial Transportation." Samsara. https://www.samsara.com/blog/4-ways-reopening-has-changed-us-commercial-transportation.
} 
lessons learned about the agency's flexibility in meeting mission requirements beyond vehicle travel. When asked about the impacts to Federal agencies at an INTERFUEL meeting, fleet managers responded that essential workers, emergency management, heath care services, shipping, and public service vehicles were operating more continuously than others, but the vast majority of vehicles were being used less frequently. One fleet manager stated that vehicle use in his fleet had been reduced by $90 \%$. Evaluating baseline operations and how they may change during different realized hazard scenarios aids in increasing fleet operations flexibility.

\subsection{Protect Fleet Assets}

Taking a risk-informed approach to resilience planning allows fleet managers to proactively protect fleet assets and mitigate damage at the time of emergency or in the aftermath of a disruptive event. Fleet managers can play a role in protecting fueling stations, fleet vehicles, and even the local electric power and transportation infrastructure from threats.

\subsubsection{Fuel}

Hazards such as flooding, wind damage, and seismic events are primary threats to fueling stations. Ensuring facilities managed by fleets follow the latest flood protection building codes, such as those developed by the American Society of Civil Engineers (ASCE), ${ }^{34}$ can reduce potential damage from flooding. The DOE has identified efforts to protect fueling infrastructure $^{35}$ that can be applied to fuel stations. These include but are not limited to:

- Raising elevation of existing fueling stations where possible

- Wrapping or raising electrical support equipment

- Securing above ground storage tanks to avoid movement during high winds or floodwaters

- Constructing floodwalls around facilities.

If forecasting provides advance knowledge of a coming hazard event, fueling stations can create temporary protections. Further, fuel management policies can help protect stations by ensuring fueling station tanks are refilled when they are half-empty. This reduces the likelihood that high winds or flood waters will move or damage the tanks, and it provides a larger supply of emergency fuel after a disturbance.

Beyond physical security for the fueling infrastructure, resilience planning should include considerations for logistical hurdles such as ingress and egress restrictions for agency and support personnel to access both onsite and offsite secured fueling infrastructure. Additionally, the fleet should consider the requirements of equipment and trained personnel to support fueling

\footnotetext{
${ }^{34}$ ASCE. Flood Resistant Design and Construction. https://ascelibrary.org/doi/book/10.1061/9780784413791.

${ }^{35}$ AOC Petroleum Support Services, Inc. 2014. United States Fuel Resiliency Volume III. https:/www.energy.gov/sites/prod/files/2015/04/f22/QER\%20Analysis\%20-

\%20United $\% 20$ States $\% 20$ Fuel $\% 20$ Resiliency $\% 20$ Volume $\% 20$ III.pdf.
} 
if fuel stations become unavailable and fuel needs to be delivered to vehicles and temporary fueling sites for an extended period.

On-site access and storage of fuels and the infrastructure and personnel to distribute the stored fuel to critical missions may provide back-up fuel for a limited period; however, the same codes and preparedness considerations apply. A continuity plan should consider how long fleet assets need to operate and how long fuel supply might be cut off. One industry expert recommends maintaining a ten-day supply of fuel, especially in advance of heavy storms. ${ }^{36}$ This may require larger fueling storage capacity, but larger storage capacity can also reduce fueling costs and increase flexibility regarding the size of deliveries. Prioritizing fuel for critical missions can significantly extend the duration of fuel supply.

Another option is to secure back-up contracts with secondary and tertiary fuel suppliers. Contracts can be structured to prioritize federal assets. Fleet managers can also negotiate Interagency Agreements for mutual fuel support where one agency might have capabilities to support other agencies in emergencies. These agreements can be established using the US Treasury G-Invoicing system, Fiscal Service Form 7600A to establish the agreement, and Fiscal Service Form $7600 \mathrm{~B}$ to exchange funds. ${ }^{37}$

The Defense Logistics Agency Energy can supply petroleum and other fuels to all Federal agencies through government procurements. ${ }^{38}$ Minimum fuel purchases are described in $41 \mathrm{CFR}$ $\S 101-26.602-3 .{ }^{39}$ The agency has experienced incidents where components in close proximity within a single agency could not share a large fuel tank in an emergency because they had no pre-negotiated an agreement. ${ }^{40}$

Some fuel suppliers can offer fuel tank trucks or tank wagons with the capability to directly refuel vehicles. However, these fuel transport and dispensing trucks are not broadly available in gasoline or diesel service and might not be available in a timely manner during emergencies. Fuel suppliers or industrial rental companies may also have diesel generators that can provide backup electric power to fueling stations. ${ }^{41}$

For emergency fueling contracts that are not used in the typical course of business, it is especially important to identify potential impediments to access such as ingress and egress restrictions that might arise during an emergency and to coordinate with site managers to ensure availability of access to these vehicles and personnel. A test run at the initiation of the contract can inform both parties in advance.

\footnotetext{
${ }^{36}$ Marc McConahy. Personal communication with the authors.

${ }^{37}$ Bureau of the Fiscal Service. "G-Invoicing." https://www.fiscal.treasury.gov/g-invoice/.

${ }^{38}$ DLA. "Federal Agencies.” https://www.dla.mil/Energy/Business/FederalAgencies/.

$3941 \mathrm{CFR} \S 101-26.602-3$.

${ }^{40}$ Marc McConahy. Personal communication with the authors.

${ }^{41}$ Marc McConahy. Personal communication with the authors.
} 


\subsubsection{Vehicles}

Vehicles can be damaged or rendered inoperable during emergencies. These risks can be minimized if fleet managers incorporate a risk-informed approach ensuring that vehicles are parked appropriately, in areas that are secure, particularly when disruptions are anticipated. These locations may include high ground in flood zones or garages for other hazards. With localized hazards such as flooding, fleets may want to relocate vehicles outside the pathway of the anticipated disruptions (Figure 8). As with fuel stations, filling vehicles before known events and having fueling policies in place to fill vehicles when half-full or when they have completed missions allows fleets to function if additional fuel becomes unavailable.

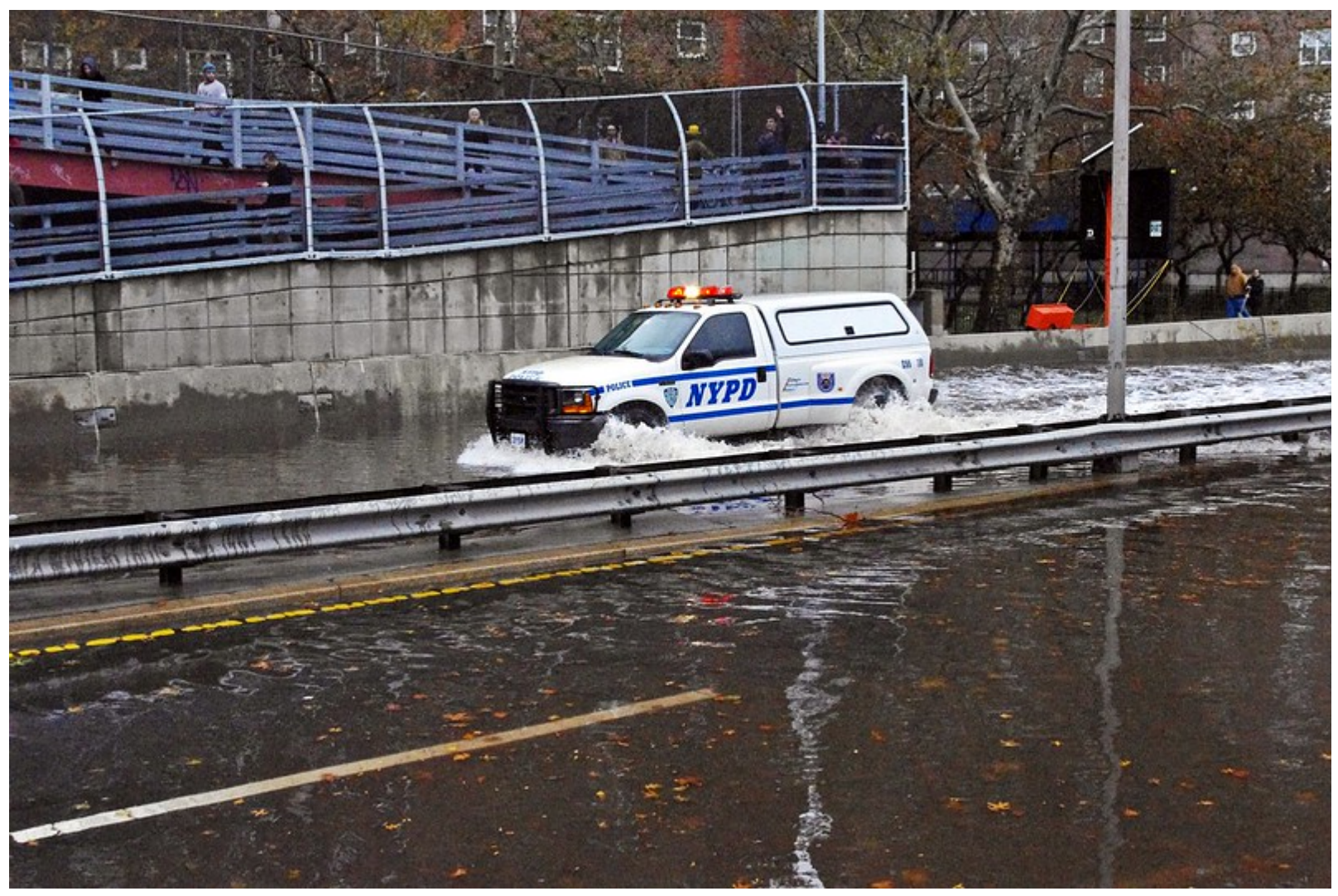

Figure 8. A truck drives through flood water in New York City after Hurricane Sandy ${ }^{42}$

Photo from David Shankbone

Fleet management capabilities beyond fleet primary assets can be protected through advanced planning. Fleet data systems can be valuable during crisis, and to ensure they are accessible during an event, with planning any onsite computing or communications capabilities can be moved to secure offsite locations or online.

\footnotetext{
${ }^{42}$ David Shankbone. 2012. "Hurricane Sandy 2012 East River." Flickr photo album. https://www.flickr.com/photos/27865228@N06/8139649191. Licensed with CC BY 2.0. To view a copy of this license, visit https://creativecommons.org/licenses/by/2.0/.
} 
Finally, cybersecurity concerns have grown as vehicles are electrified and increasingly connected to information networks. Fleets should follow cybersecurity best practices as laid out in the FEMP Federal Fleet report, Vehicle Cybersecurity Threats and Mitigation Approaches. ${ }^{43}$

\subsubsection{Electricity and Transportation Infrastructure}

Electric power is needed for fueling stations to operate and can be affected by numerous hazards. Protecting this infrastructure often involves burying or reinforcing powerlines ${ }^{44}$ or installing protected onsite energy generation with energy storage systems. Critical roads, bridges, and tunnels upon which fleets rely can be damaged by delayed maintenance, earthquakes, landslides, and flood erosion among other causes. Advocating for proper maintenance of this infrastructure supports fleet continuity. The National Institute of Standards and Technology (NIST) within the Department of Commerce highlights ${ }^{45}$ the opportunity to include multimodal transportation planning such as bike lanes when updating infrastructure. These efforts allow extra space for a vehicle if a roadway is damaged and increases room for the deployment of services through bicycle, motorized bicycles, or neighborhood electric vehicles during an event. Solutions such as these also support the flexibility continuity goal.

Electric power is required to maintain fueling for all fuels, with exceptions for gravity-flow liquid tanks or direct fueling from tank wagons with that capability. Onsite generators at fueling stations are frequently the solution to providing electric power in times of grid power outages. As an example, the state government of Florida has targeted key fueling stations along evacuation routes with mandates to install back-up generators. ${ }^{46}$ Generators most often operate on diesel or natural gas, but it is possible to install generators that operate on onsite alternative fuel.

\footnotetext{
${ }^{43}$ EERE. "Federal Fleet Cybersecurity.” https://www.energy.gov/eere/femp/federal-fleet-cybersecurity.

${ }^{44}$ U.S. Department of Energy Office of Energy Policy and Systems Analysis. 2015. Climate Change and the U.S. Energy Sector: Regional Vulnerabilities and Resilience Solutions. https://www.energy.gov/sites/prod/files/2015/10/f27/Regional_Climate_Vulnerabilities_and_Resilience_Solutions $0 . p d f$.

${ }^{45}$ https://www.nist.gov/publications/community-resilience-planning-guide-buildings-and-infrastructure-systemsvolume-ii.

${ }^{46}$ AOC Petroleum Support Services, Inc. 2014. United States Fuel Resiliency Volume III. https:/www.energy.gov/sites/prod/files/2015/04/f22/QER\%20Analysis\%20\%20United $\% 20$ States $\% 20$ Fuel $\% 20$ Resiliency $\% 20$ Volume $\% 20$ III.pdf.
} 
Back-up electricity generation allows facilities to operate independently from the broader electric grid. As an example, New York State is taking this concept further and has prioritized improving the electric grid to better incorporate distributed, renewable electricity generation and to allow islanding portions of the system ${ }^{47}$ to operate independently from the broader grid in an emergency.

The installation-wide continuity effort at Marine Corps Air Station Miramar is developing a microgrid ${ }^{48}$ that includes on-site generation from numerous

PEVs can provide energy back to buildings in an emergency if they are part of a microgrid and vehicle-to-grid charging units are installed. Hydrogen fuel cell electric vehicles can provide the same services as well. In these cases, the fleet can be used to power critical facilities in an emergency, although it will require that those fleet assets remain parked. Vehicle-to-grid charging units can provide power as long as the PEVs can provide electricity. Most 2020 all-electricvehicle battery packs hold 60 kWh or less. distributed sources. The diversity of generation and advanced control of electric load allows the installation to function independently and, as a benefit to fleet operations, continue to provide power to fueling stations and even provide charging capability to plug-in electric vehicles (PEVs) in the event of a broader emergency affecting the grid.

\subsection{Incorporate Fleet Fuel Diversification}

Incorporating alternative fuel vehicles (AFVs) in the fleet increases fueling options for fleets and can help to alleviate fueling supply constraints. Pathways have been documented ${ }^{49}$ for numerous vehicle fuels, from their origin through processing and distribution to fueling sites and ultimately to use in vehicles (Figure 9).

\footnotetext{
${ }^{47}$ NYS 2100 Commission. Recommendations to Improve the Strength and Resilience of the Empire State's Infrastructure. https://www.governor.ny.gov/sites/governor.ny.gov/files/archive/assets/documents/NYS2100.pdf. ${ }^{48}$ Rickerson, Wilson, Michael Wu, and Meredith Pringle. 2018. Beyond the Fenceline. https://www.researchgate.net/publication/328839185_Beyond the Fence_Line Strengthening_Military_Capabilitie s Through_Energy_Resilience_Partnerships.

${ }^{49}$ Johnson, Caley. 2019. "Fuel Diversification to Improve Transportation Resilience: a Backgrounder." Presented at the Transportation Fuel Resilience in Tampa Bay Workshop, March 25, 2019.

https://afdc.energy.gov/files/u/publication/fuel_diversification_for_resiliency.pdf.
} 


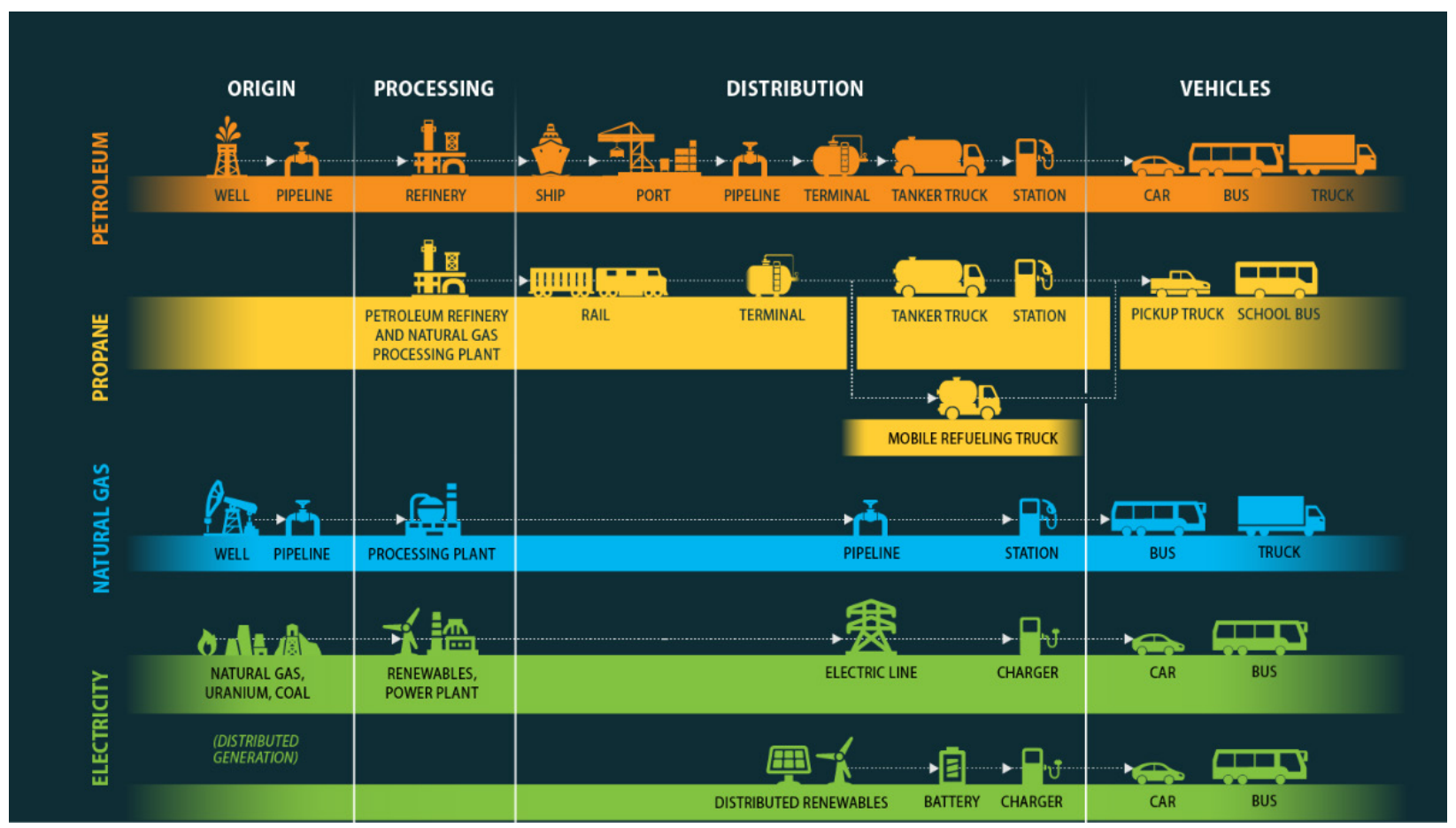

Figure 9. Transportation fuel pathways ${ }^{50}$

IIlustration from NREL

Fuel specific benefits vary by fuel type. If proper infrastructure and planning is in place, the existing natural gas underground pipeline infrastructure can supply fueling stations even when surface damage may block tanker trucks from reaching a station. Existing mobile refueling trucks are often used for propane refueling through wet-hosing, which may allow the capability to bring the fuel to a stranded vehicle during an emergency. Perhaps most prominent, PEVs charge from the extensive electric grid which provides electricity from diverse generation sources.

Individual site fuel support varies as well and should be considered during resilience planning. Certain sites have access to multiple electrical distribution feeders or natural gas pipeline feeds, and others have multiple avenues of entry for petroleum or propane tankers. If based within a microgrid, PEVs with vehicle-to-grid capabilities can export power to buildings when other sources are unavailable. They can also be used as power sources for emergency shelters.

Several alternative fuel technologies have the added benefit of the capability to operate on multiple fuel types. These technologies include E85 flex-fuel vehicles, CNG bi-fuel vehicles, and plug-in hybrid vehicles. Additionally, diesel vehicles are often capable of operating on biodiesel. These vehicles provide flexible assets to the fleet during an emergency.

50 ibid. 
State energy offices have made fuel diversification a common resilience goal in their transportation sectors. ${ }^{51}$ The benefits of diversifying fuel use have led the state of New York to create twin primary transportation resilience goals of increasing alternative fuel capable vehicles and increasing alternative fuel use. ${ }^{52}$

The continuity goal of increased fuel diversity aligns with existing Federal fleet mandates which require fleets to:

- Acquire AFVs as directed by EPAct 1992 Section $303^{53}$

- Use alternative fuel in dual-fueled AFVs as directed by EPAct 2005 Section $701^{54}$

- Increase alternative fuel use as directed by EISA Section $142^{55}$

- Install alternative fuel infrastructure as directed by EISA Section $246 .{ }^{56}$

Federal fleets already working to achieve these goals are actively engaged in continuity efforts. Fleet regulations often exempt law enforcement and emergency response vehicles from alternative fuel requirements. However, strategically targeting these vehicles for alternative fuel use can have a benefit for fleet continuity.

\subsection{Increase Fleet Efficiency}

Increasing fleet efficiency involves meeting mission objectives while minimizing fleet fuel consumption. Furthermore, during a disruption where fuel supplies are limited, more efficient vehicles will be able to travel farther to meet mission objectives than less efficient vehicles. Additionally, increasing efficiency leverages the co-benefits of reliability and optimization solutions in the resilient-efficient-secure nexus for fleet resilience planning.

The Federal fleet has existing mandates aligned with increasing fleet efficiency including the following directives:

- Reduce annual fleet petroleum consumption as directed in EISA Section $142^{57}$

- Acquire efficient low greenhouse gas emitting vehicles as directed in EISA Section $141^{58}$

- Right-size vehicles for mission requirements through a vehicle allocation methodology as suggested in GSA FMR Bulletin B-43.

\footnotetext{
${ }^{51}$ AOC Petroleum Support Services, Inc. 2014. United States Fuel Resiliency Volume III. https://www.energy.gov/sites/prod/files/2015/04/f22/QER\%20Analysis\%20\%20United $\% 20$ States $\% 20$ Fuel $\% 20$ Resiliency\%20Volume $\% 20$ III.pdf.

52 NYS 2100 Commission. Recommendations to Improve the Strength and Resilience of the Empire State's Infrastructure. https://www.governor.ny.gov/sites/governor.ny.gov/files/archive/assets/documents/NYS2100.pdf.

5342 U.S.C. $\S 13212(\mathrm{~b})$

5442 U.S.C. $\$ 6374(a)(3)(E)$

5542 U.S.C. $\$ 6374 \mathrm{e}(\mathrm{a})(2)$

5642 U.S.C. $\S 17053(\mathrm{a})$

5742 U.S.C. $\$ 6374 \mathrm{e}(\mathrm{a})(2)$

5842 U.S.C. $\S 13212(\mathrm{f})(2)$
} 


\subsection{Increase Transparency by Refining Fleet Data Management}

At the time of a disruption, reliable, real-time data allows fleet managers the ability to understand the status and availability of assets. More broadly, good data management allows fleets to meet mission requirements more efficiently. As described in section 3.3 fleets are already engaged in fleet data management and are subject to a mandate to use an FMIS capable of providing fleet operations data for all reporting requirements as directed in GSA's FMR 41 CFR 102-34.340.

A fleet FMIS provides an excellent resource when working in planning stages with continuity partners to describe the extent of fleet operations and baseline fleet requirements for emergency response.

Telematics provides real-time visibility into fleet operations which can be invaluable during an emergency. FEMP has detailed the broad potential applications and benefits of vehicle telematics. ${ }^{59}$ Notable specific resilience benefits of telematics services include the capability to locate fleet vehicles and track their operational status such as any relevant maintenance requirements and fuel levels.

\subsection{Collaborate and Communicate With Stakeholders}

Section 3.2 introduced the benefit of collaborating with local and regional partners in advance of an emergency. If fleets face severe disruptions, these partnerships may provide additional flexibility and allow for clear coordination during crisis response and throughout restoration efforts. Collaboration to enable fuel availability is the primary focus in this section.

A functional example of the benefits of collaborations are state level Fuels Set-Aside programs which direct fuel to state and local government emergency response missions in the event of fuel shortages. ${ }^{60}$ Depending on the fleet and specific mission this type of advance agreement provides the fleet increased fuel security. Increased fuel security again invokes the resilient-efficientsecure nexus, allowing fleet managers to harness the multiple co-benefits of collaboration and increased security to increase the fleet resilience.

The Clean Cities Coalition Network ${ }^{61}$ works towards many of the same goals of Federal fleet mandates. The effort is primarily focused on implementing alternative fuel and advanced vehicles and is comprised of local coalitions of public and private stakeholders. Similarly, the State and Alternative Fuel Provider Fleets ${ }^{62}$ share these goals. As Federal fleets work to implement these technologies themselves, coordinating with local coalitions and partners to install private alternative fuel infrastructure, or pool demand for new public infrastructure can

\footnotetext{
${ }^{59}$ Hodge, Cabell, and Mark Singer. 2017. Telematics Framework for Federal Agencies: Lessons from the Marine Corps Fleet. Golden, CO: NREL. NREL/TP-5400-70223. https://www.nrel.gov/docs/fy18osti/70223.pdf.

${ }^{60}$ NASEO. 2018. GUIDANCE FOR STATES ON PETROLEUM SHORTAGE RESPONSE PLANNING. Arlington, VA. https://naseo.org/data/sites/1/documents/publications/Petro\%20Shortage $\% 20 \mathrm{Planning} \% 20 \mathrm{Feb} \% 202018$.pdf.

${ }^{61}$ EERE. "Clean Cities Coalition Network.” https://cleancities.energy.gov/.

${ }^{62}$ EERE. "State \& Alternative Energy Fuel Provider Fleets.” https://epact.energy.gov/.
} 
decrease infrastructure costs. Agreements to share infrastructure or provide emergency access to infrastructure increases fueling options and fleet continuity.

As PEVs begin to be used by fleets in larger numbers, electricity supply becomes more important. Aside from direct charging of vehicles, electricity is required for all standard fueling stations. Collaborating with local utilities and agency facilities management can help these entities appropriately prioritize fleet requirements during a disruption.

\subsection{Integrate Fleet Planning in Agency Resilience Efforts}

Fleets interact with broader agency missions and are directly tied to facilities through fueling and garages in many cases. In some instances, fleets may play a direct role in facilities maintenance. Secure facility access to electricity, natural gas, and other fuels may be necessary to ensure fleet continuity. Furthermore, PEVs can be integrated as a source of emergency power at facilities with microgrids or island-capable buildings.

Fleet managers may need to coordinate internally with leadership to set up continuity transportation plans for federal staff to access and navigate the site in case of an event. These plans could include transportation services such as shuttles and route alternatives in case of damaged transportation infrastructure such as bridges and roadways.

Most importantly, facility resilience planning efforts are more common than parallel fleet efforts. Fleet managers can learn from their energy manager counterparts and build on their continuity structures and resilience planning efforts. Integrating fleets into holistic planning can thus ensure a more robust and effective planning process. 


\section{Conclusions}

The Federal fleet operates across the country and meets agency mission requirements that include national defense, land management, healthcare, postal delivery, and many other tasks. Fleet operations face diverse risks from natural hazards, technological failures, and human caused events that can disrupt mission capability. Special use law enforcement and emergency response vehicles are not the only vehicles with roles during emergency. Fifteen agencies have emergency response responsibilities defined by FEMA when events affect energy and transportation sectors.

Fleet resilience seeks to (1) protect fleet operations from small disruptions through a robust infrastructure, (2) maintain fleet operations during moderate disruptions through redundant systems, (3) return the fleet to full operations as quickly as possible after severe disruptions following a recovery plan, and (4) mitigate or minimize damage through resourcefulness. Fleet managers can best support fleet resilience by including continuity and resilience goals throughout the cyclical fleet management process of plan, collect, strategize, and implement. Initial continuity scoping exercises should include planning for disruptions affecting vehicles, fueling stations, transportation infrastructure, and the electric grid. Creating baselines of fleet operations that identify fleet priority assets and infrastructure will allow fleets to appropriately target resilience improvement efforts.

Fleet resilience considerations and strategies align with existing fleet goals of reduced petroleum consumption, increased alternative fuel use, and improved fleet management based on quality data. These efforts make the fleet operate more efficiently and with flexibility which benefit fleet operations during a disruption. Similarly, fleet resilience aligns with broader resilience efforts and energy management. Thus, the steps outlined in the TRN, though not specific to fleet, are able to be implemented by fleet managers during the resilience planning process.

Improving fleet continuity requires the identification and implementation of considerations and strategies covering fleet-specific assets and through broader collaboration with partners beyond the fleet community. Fleets can proactively secure their mission capability by protecting vehicles and infrastructure from known risks and installing generators or islandable distributed energy resources at fueling stations to provide back-up power should hazards affect the grid. Collaborating with partner fleets to install and allow access to fueling infrastructure provides increased fuel availability during disruptions. Fleets have specific visibility into transportation and electric grid infrastructure that they rely on and can advocate for their maintenance and reinforcement. Finally, as electric grids modernize and work towards the benefits of microgrids and islanding, fleets can engage with facilities and utility partners to ensure fleet requirements are met and that the benefits of fleet assets including PEVs are incorporated in these plans. Federal fleets should develop resilience plans or incorporate transportation assets into overall agency plans as described in Table 1. An agency resilience plan should identify key stakeholders, define critical fleet vehicles and infrastructure, assess risk, and identify mechanisms to reduce 
disruptions and continue operations during and after an emergency. Fleet managers should plan for and address the potential for events and factors that may disrupt their ability to maintain continuity of fleet mission capabilities when events occur.

Table 1. Template for fleet resilience plan

\begin{tabular}{|c|c|}
\hline Categories & Actions \\
\hline $\begin{array}{l}\text { Identify } \\
\text { Stakeholders }\end{array}$ & $\begin{array}{l}\text { Collaborate with agency fleet manager, site fleet managers, site facility managers, } \\
\text { resilience officers, local government fleet managers, fuel providers, site leadership, } \\
\text { personnel with essential job functions reliant on fleets }\end{array}$ \\
\hline \multirow[t]{2}{*}{ Scope } & $\begin{array}{l}\text { Baseline fleet vehicles, fueling stations and supporting infrastructure including } \\
\text { station power source, critical road infrastructure including single points of failures }\end{array}$ \\
\hline & Identify emergency response, law enforcement, and other mission-critical vehicles \\
\hline Risks & $\begin{array}{l}\text { Identify potential (1) natural and human caused hazards, }(2) \text { human caused threats, } \\
\text { and ( } 3 \text { ) vulnerabilities or insufficient existing protections from the identified threats } \\
\text { and hazards. }\end{array}$ \\
\hline \multirow[t]{8}{*}{ Considerations } & $\begin{array}{l}\text { Prioritize vehicles, fuel supplies, and transportation infrastructure that support critical } \\
\text { missions }\end{array}$ \\
\hline & $\begin{array}{l}\text { Identify options to perform tasks remotely, develop agreements with local officials to } \\
\text { provide and receive emergency support }\end{array}$ \\
\hline & $\begin{array}{l}\text { Protect key assets including vehicles, fuel, electricity, and transportation } \\
\text { infrastructure if applicable }\end{array}$ \\
\hline & $\begin{array}{l}\text { Back up critical vehicles either through agreements with external partners or } \\
\text { maintain excess inventory }\end{array}$ \\
\hline & $\begin{array}{l}\text { Diversify fuels by acquiring dual-fueled vehicles and select most reliable fuel based } \\
\text { on access }\end{array}$ \\
\hline & $\begin{array}{l}\text { Select most efficient vehicles with longest driving range, such as gasoline hybrid } \\
\text { vehicles }\end{array}$ \\
\hline & $\begin{array}{l}\text { Improve transparency into fleet assets at the national level and between local } \\
\text { community partners }\end{array}$ \\
\hline & $\begin{array}{l}\text { Collaborate with facility managers and resilient officers to integrate fleet into } \\
\text { overarching energy resilience plan }\end{array}$ \\
\hline Approach & $\begin{array}{l}\text { Prioritize and implement strategies based on their ability to address key risks and } \\
\text { enable critical missions while considering implementation ease and costs. }\end{array}$ \\
\hline
\end{tabular}

Fleet managers can incorporate resilience into fleet planning by leveraging lessons learned from tools like the TRN and processes like 50001 Ready. This can include baseline development, risk assessment, developing solutions, prioritizing strategies, and preparing a roadmap to action for the fleet. 


\section{References}

Akhtar, Ali. 2020. "4 Ways Reopening Has Changed U.S. Commercial Transportation." Samsara Data Insights. June 16, 2020. https://www.samsara.com/blog/4-ways-reopening-haschanged-us-commercial-transportation.

AASHTO (American Association of State Highway and Transportation Officials). n.d. "Resilient and Sustainable Transportation Systems Technical Assistance Program: Climate Change Mitigation/Adaptation State-by-State Interactive Map.” Accessed October 5, 2020. https://environment.transportation.org/center/rsts/state by_state_map.aspx.

ASCE (American Society of Civil Engineers). 2014. "Flood Resistant Design and Construction (24-14)." Accessed October 5, 2020. https://ascelibrary.org/doi/book/10.1061/9780784413791.

DLA (Defense Logistics Agency). n.d. "Federal Agencies.” Accessed March 15, 2021. https://www.dla.mil/Energy/Business/FederalAgencies/.

DOE (U.S. Department of Energy). 2014. United States Fuel Resiliency - U.S. Fuels Supply Infrastructure Study: (III) Vulnerability and Resilience. Prepared by Intek, Inc. for the U.S. Department of Energy, September 2014. https:/www.energy.gov/sites/prod/files/2015/04/f22/ QER\%20Analysis\%20-\%20United\%20States\%20Fuel\%20Resiliency\%20Volume\%20III.pdf.

DOE. 2015. Climate Change and the U.S. Energy Sector: Regional Vulnerabilities and Resilience Solutions. Washington, D.C.: DOE. https://www.energy.gov/sites/prod/files/2015/ 10/f27/Regional_Climate_Vulnerabilities and Resilience_Solutions 0.pdf.

DOE Advanced Manufacturing Office. n.d. "50001 Ready Navigator." Accessed October 5, 2020. https://navigator.lbl.gov.

DOE Federal Energy Management Program. n.d. "About the TRN.” Accessed October 5, 2020. https://trn.pnnl.gov/about.

DOE Federal Energy Management Program. n.d. "Federal and Utility Collaboration.” Accessed October 5, 2020. https://www.energy.gov/eere/femp/federal-utility-partnership-working-group.

DOE Federal Energy Management Program. n.d. "Federal Automotive Statistical Tool." Accessed October 5, 2020. https://fastweb.inl.gov/.

DOE Federal Energy Management Program. 2020. "Federal Best Practices: Core Principles of Sustainable Fleet Management.” November 2020. https://www.energy.gov/sites/prod/files/2020/11/f80/federal-best-practices-sustainable-fleet.pdf.

DOE Federal Energy Management Program. n.d. "Federal Fleet Shuttle Stops around Washington, D.C." Accessed October 5, 2020. https://www.energy.gov/eere/femp/federal-fleetshuttle-stops-around-washington-dc. 
DOE Federal Energy Management Program. n.d. "Fleet Sustainability Dashboard.” Accessed October 5, 2020. https://federalfleets.energy.gov/FleetDASH.

DOE Federal Energy Management Program. n.d. “Glossary.” Accessed October 5, 2020. https://trn.pnnl.gov/glossary.

DOE Federal Energy Management Program. n.d. "Interagency Committee on Alternative Fuels and Low Emission Vehicles (INTERFUEL) Working Group.” Accessed October 5, 2020. https://www.energy.gov/eere/femp/interagency-committee-alternative-fuels-and-low-emissionvehicles-interfuel-working-group.

DOE Federal Energy Management Program. n.d. “Technical Resilience Navigator.” Accessed October 5, 2020. https://trn.pnnl.gov.

DOE Vehicle Technologies Office. n.d. “Clean Cities Coalition Network.” Accessed October 5, 2020. https://cleancities.energy.gov/.

DOE Vehicle Technologies Office. n.d. "State and Alternative Fuel Provider Fleets." Accessed October 5, 2020. https://epact.energy.gov/.

FEMA (Federal Emergency Management Agency). 2016. Emergency Support Function \#1Transportation Annex. https://www.fema.gov/sites/default/files/202007/fema_ESF_1_Transportation.pdf.

FEMA. 2016. Emergency Support Function \#12-Energy Annex. https://www.fema.gov/sites/default/files/2020-07/fema_ESF_12_Energy-Annex.pdf.

FEMA. 2020. "Federal Interagency Operational Plans.” Last modified September 21, 2020. https://www.fema.gov/emergency-managers/national-preparedness/frameworks/federalinteragency-operational-plans.

FEMA. 2020. "National Response Framework.” Last modified July 31, 2020. https://www.fema.gov/emergency-managers/national-preparedness/frameworks/response.

FEMA. 2020. "Stafford Act.” Last modified July 15, 2020.

https://www.fema.gov/disasters/stafford-act.

Filosa, Gina, Amy Plovnick, Leslie Stahl, Rawlings Miller, and Don Pickrell. 2017. Vulnerability Assessment and Adaptation Framework, Third Edition. Prepared by Volpe National Transportation Systems Center, U.S. Department of Transportation, for the Federal Highway Administration. https://www.fhwa.dot.gov/environment/sustainability/ resilience/adaptation framework. 
Govinfo. "Federal Fleet Conservation Requirements. 42 U.S.C. § 6374e(a)(2)."

https://www.govinfo.gov/app/details/USCODE-2009-title42/USCODE-2009-title42-chap77subchapIII-partH-sec6374e.

Govinfo. "Procurement of gasoline, fuel oil (diesel and burner), kerosene, and solvents. 41 CFR $\S$ 101-26.602-3." https://www.govinfo.gov/app/details/CFR-2012-title41-vol2/CFR-2012-title41vol2-sec101-26-602-3.

GSA (General Services Administration). 2017. “GSA BULLETIN FMR B-43 MOTOR VEHICLE MANAGEMENT.” https://www.gsa.gov/cdnstatic/FMR_Bulletin_B-43.pdf.

GSA. "Federal Fleet Report. GSA FMR Part § 102.34.335.” https://www.gsa.gov/policyregulations/regulations/federal-management-regulation-fmr/idtopicx2x16284\#i466051.

GSA. "Federal Fleet Report. GSA FMR Part 102.34.340.” https://www.gsa.gov/policyregulations/regulations/federal-management-regulation-fmr/idtopicx2x16284\#i466051.

Hodge, Cabell, Konrad Hauck, Shivam Gupta, and Jesse Bennett. 2019. Vehicle Cybersecurity Threats and Mitigation Approaches. Golden, CO: National Renewable Energy Laboratory. NREL/TP-5400-74247. https://www.nrel.gov/docs/fy19osti/74247.pdf.

Hodge, Cabell, and Mark Singer. 2017. Telematics Framework for Federal Agencies: Lessons from the Marine Corps Fleet. Golden, CO: National Renewable Energy Laboratory. NREL/TP5400-70223. https://www.nrel.gov/docs/fy18osti/70223.pdf.

Hotchkiss, Eliza, and Alex Dane. 2019. Resilience Roadmap: A Collaborative Approach to Multi-Jurisdictional Resilience Planning. Golden, CO: National Renewable Energy Laboratory. NREL/TP-6A20-73509. https://www.nrel.gov/docs/fy19osti/73509.pdf.

Johnson, Caley. 2019. "Fuel Diversification to Improve Transportation Resilience: a Backgrounder." Presented at the Transportation Fuel Resilience in Tampa Bay Workshop, March 25, 2019. NREL/PR-5400-73743. https://afdc.energy.gov/files/u/publication/

fuel_diversification_for_resiliency.pdf.

Justia. "Minimum Federal Fleet Requirement. 42 U.S.C. $§ 13212(f)(2) . "$ https://law.justia.com/codes/us/2001/title42/chap134/subchapi/sec13212.

Keierleber, Mark. 2015. "Photo History: After Katrina, Devastation and Renewal Inside New Orleans' Schools." The 74. August 25, 2015. https://www.the74million.org/article/photo-historyafter-katrina-devastation-and-renewal-inside-new-orleans-schools/.

Legal Information Institute. "Federal Fleet Fueling Centers. 42 U.S.C. § 17053(a)." https://www.law.cornell.edu/uscode/text/42/17053. 
Legal Information Institute. "Minimum Federal Fleet Requirement. 42 U.S.C. § 13212(b)." https://www.law.cornell.edu/uscode/text/42/13212.

NASEO (National Association of State Energy Offices). n.d. "iRev - Initiative for Resiliency in Energy Through Vehicles.” Accessed October 5, 2020. https://www.naseo.org/irev.

National Weather Service. n.d. "Floods in Colorado." Accessed October 5, 2020. https://www.weather.gov/safety/flood-states-co.

McAllister, Therese. 2016. Community Resilience Planning Guide for Buildings and Infrastructure Systems Volume II. NIST Special Publication 1190, Revision 1. May 2016. https:/www.nist.gov/publications/community-resilience-planning-guide-buildings-andinfrastructure-systems-volume-ii.

Marc McConahy, personal communication with the authors, October 1, 2020.

NYS 2100 Commission. 2013. "Recommendations to Improve the Strength and Resilience of the Empire State's Infrastructure.” January 2013. https://www.governor.ny.gov/sites/ governor.ny.gov/files/archive/assets/documents/NYS2100.pdf.

Rasmussen, Benjamin, Rawlings Miller, Erica Simmons, and Katie Lamoureux. 2018. U.S. Forest Service Transportation Resiliency Guidebook: Addressing Climate Change Impacts on U.S. Forest Service Transportation Assets. Prepared by Volpe National Transportation Systems Center, U.S. Department of Transportation, for the U.S. Forest Service. https://www.volpe.dot.gov/FS-Transportation-Resiliency-Guidebook.

Rickerson, Wilson, Michael Wu, and Meredith Pringle. 2018. Beyond the Fence Line: Strengthening Military Capabilities Through Energy Resilience Partnerships. Published by the Association of Defense Communities.

https://www.researchgate.net/publication/328839185_Beyond the Fence_Line_Strengthening Military_Capabilities_Through_Energy_Resilience_Partnerships.

Schaper, David. 2017. “10 years After Bridge Collapse, America Is Still Crumbling.” NPR. August 1, 2017. https://www.nprillinois.org/post/10-years-after-bridge-collapse-america-stillcrumbling\#stream $/ 0$.

U.S. Code. "Alternative Fuel Use by Light Duty Federal Vehicles. 42 U.S.C. $§$ 6374(a)(3)(E)." https://uscode.house.gov/view.xhtml?req=(title:42\%20section:6374\%20edition:prelim).

U.S. Department of the Treasury Bureau of the Fiscal Service. n.d. "G-Invoicing." Accessed March 15, 2021. https://www.fiscal.treasury.gov/g-invoice/.

Wrobel, Jay, Olwen Huxley, Soudeh Motamedi, Brad Gustafson, Joan Hughes, Michael Socks, and Clay Hoover. "50001 Ways to Save Energy and Support Mission.” Energy Exchange 2020. 
